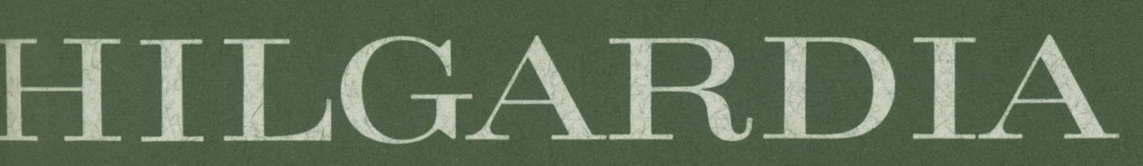

A JOURNAL OF AGRICULTURAL SCIENCE PUBLISHED BY THE CALIFORNIA AGRICULTURAL EXPERIMENT STATION

Volume 35, Number $8 \cdot$ November, 1963

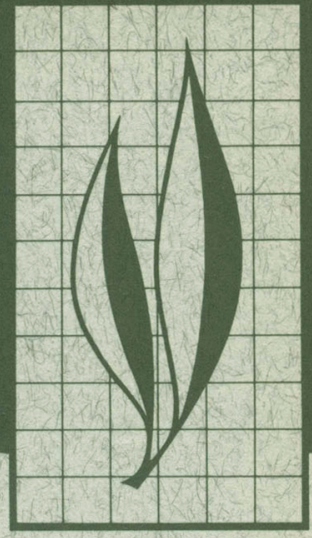

\title{
Prey-Predator Interactions in Self-Balanced Laboratory Populations
}

S. E. Flanders and M. E. Badgley 
The establishment of a self-perpetuating animal association in an environment that is abiotically uniform appears to be essential for ascertaining and understanding the principles of biotic regulation of populations. If this association so established is of a simple type, such as that of a plant-feeding insect under regulation by one of its natural enemies, the isolation of basic regulatory factors and a study of the operation of each, free of the extraneous or secondary factors which confuse relationships under natural conditions, is possible.

Organisms that are eminently suitable for this purpose because they perform as well in the laboratory as in nature are the flour moth, Anagasta kübniella (Zell.); the predatory mite, Blattisocius tarsalis (Berlese) and the parasitic wasp, Exidechtbis canescens (Grav.).

Populations of these animals, when placed together, are selfperpetuating and self-regulating and form a permanent ecosystem if periodically provided with adequate amounts of nonviable plant material, such as processed grains of wheat. The ecosystem then consists of one or two "food chains," the wheat being fed upon by the caterpillar and the caterpillar being fed upon by the parasite; the caterpillar that escapes parasitic attack becomes a moth whose eggs are fed upon by the predatory mite.

In the Anagasta ecosystem, the population of each organism attains a numerical balance with its numbers fluctuating around an average density. This average density, however, varies not only with the kind of organism but with the type of regulatory mechanism which may be either the amount of food (food depletion), predatism or parasitism. These mechanisms and the sequence in which they operate can be manipulated by modifying the abiotic environmental factors that determine the extent and frequency of contact between prey and natural enemy. Consequently, the interaction of such populations may be rendered either numerically regulative or numerically nonregulative. The operation of one mechanism may either preclude or supplement the operation of another.

continued Inside back cover

\section{THE AUTHORS:}

S. E. Flanders is Professor of Biological Control and Entomologist, Emeritus, Citrus Research Center and Agricultural Experiment Station, Riverside, and M. E. Badgley is Laboratory Technician II, Citrus Research Center and Agricultural Experiment Station, Riverside. 


\section{Prey-Predator Interactions in Self-Balanced Laboratory Populations ${ }^{1,2}$}

\section{INTRODUCTION}

THE ABILITY of various animals to exist together while drawing upon a common pool of resources is one of the central unsolved problems in population dynamics (Elton, 1946). "We simply do not understand exactly why populations of, say, a Pentatomid bug, a grasshopper, a moth caterpillar, a vole, a rabbit, and an ungulate should be able to draw upon the same common resource (grassland vegetation) and yet... form a stable animal community over long periods of years." Forests contain hundreds of potentially injurious animal species in economically insignificant numbers (Graham, 1939). As stated by Darwin in his "Origin of Species," the face of nature remains for long periods uniform because the mortality of a species and its tendency to increase are in the long run so nicely balanced. $\mathrm{Ob}$ viously, as pointed out by Elton (1946), when the biomass of vegetation greatly exceeds that of the animals dependent upon it, as is generally the case, the increase of the animal population is usually limited by factors other than food.

One such factor mentioned by Darwin is the predator-prey interaction. Darwin was cognizant of the fact that the average number of an animal species may be very frequently determined by its serving as prey to other animals. According to Nicholson (1954a), attack by predators is probably the major influence which prevents phytophagous animals from reducing the earth's vegetation to extreme sparseness. Riley (1893) pointed out that wherever the conditions of life are unchanged by man's actions, the relations between the plantfeeder and the predaceous and parasitic species of its own class remain substantially the same year in and year out, whatever the fluctuation between them for any given year. This natural equilibrium which characterizes all elements of the plant and animal world is the basis for the utilization of the predatorprey interactions to conserve plant life, a common practice in agriculture and forest management (Clausen, 1956; Pickett, 1960). The term predator as used in this discussion may or may not include the entomophagous parasite. Wheeler (1928) considered the entomophagous parasite to be a "refined" predator. Nicholson (1933) stated that it is a special kind of predator because the number of hosts that it finds determines the number of hosts destroyed by its offspring.

\footnotetext{
${ }^{1}$ Submitted for publication March 29, 1963.

${ }^{2}$ Paper No. 1471 of the California Citrus Research Center and Agricultural Experiment Station, Riverside, California.
} 
The predator, when regulating the abundance of a phytophagous prey, necessarily precludes plant life from regulating the prey's abundance. When this is the case, plant life assumes the status of an unlimited resource, the conservation of plant life being the ecological effect of a reciprocal interaction of the phytophagous animal and its natural enemy, the predator. The role of such reciprocal interactions in the maintenance of the prey-predator equilibria was pointed out by Marchal (1908).

The predator, if its action is preyregulative, necessarily regulates its own abundance through its effect on the governing resource (the prey). However, such self-regulation of an animal population is probably the most contentious question in animal ecology
(Nicholson, 1958). Yet it is very evident, as pointed out by Woodworth (1908), that species maintain themselves for ages with the ratio between the birth rate and premature death not varying an appreciable fraction of a per cent.

Apparently, the ecologist concerned with population equilibrium ("balance in nature") has in mind its two complementary aspects: (1) the prevailing abundance and uniformity of plant life, in general, despite the many kinds of animals nutritionally dependent upon it; and (2) the occurrence of animal life at population densities which render its food supply in effect unlimited. These aspects may have been the basis for Williamson's (1957) general proposition that it is possible to have as many species as there are controlling factors.

\section{NATURAL VS. ARTIFICIAL ECOSYSTEMS}

In nature, the obscurity of the causes which restrict the increase of animal populations and thus permit their coexistence on a given amount of plant life is, as stated by Smith (1935), the result of population densities being determined by the interaction of almost countless forces continually varying in intensity, the effect of each force influencing in some degree the effect of every other force. On considering these forces in detail, it seemed to Smith an almost hopeless task to attempt to understand their effect on population densities even when most of them appeared to be secondary, merely modifying the intensities of a few primary forces.

These forces are recognizable in the study of ecosystems, interacting associations of self-perpetuating organisms that are supported and circumscribed by particular physico-chemical environments. The great complexity of a natural ecosystem compels the ecologist, who wishes to observe the operation of the primary forces separately, to establish one or more artificial ecosystems in which such forces can be isolated, measured and evaluated.

It is noteworthy that the ecosystem was inferentially described in 1869 by the German biologist Haeckel in his definition of ecology, this being the relation of an animal to its organic as well as its inorganic environment, including above all its "friendly" or "hostile" relations to those plants or animals with which it comes directly or indirectly in contact (vide Park, 1946). Implicit in this relationship is the existence of balanced populations wherein deaths equal births with population increases and decreases correlated with "friendly" or "hostile" factors.

Park (1946) has pointed out that the artificiality of a laboratory ecosystem does not necessarily invalidate the principles of population dynamies demonstrated therein, provided that the animals and experimental conditions are properly selected.

Fortunately, certain animals, both prey and predator, are so well adapted to artificial environments that they are 
able to perpetuate themselves and to persist indefinitely in such environments. Fortunately, also, the few primary forces that regulate the densities of self-perpetuating persistent populations operate as well in artificial as in natural ecosystems, free of the numerous secondary forces that prevail in nature.

Gause (1934) stated that in artificial environments, by maintaining the total amount of energy at a constant level through continually changing the nutritive medium at fixed intervals of time, we approach natural conditions where the inflow of solar energy is maintained at a fixed level [the earth's biomass represents about 0.1 per cent of the intercepted solar energy (Varley, 1960)], conditions such that we can study for a period of any duration the process of competition for a common food and the destruction of one species by another.

For the maintenance of population equilibrium (balance) in the laboratory ecosystem, the prey-predator relation must be physiologically and ecologically complete (Flanders, 1953). Also, as pointed out by Wallace in 1858 (Bates and Humphery, 1956) for species in nature, if the prey is not to be annihilated by its "most dangerous" predators, it must have some degree of protection.

In nature this protection is attained directly either through the interposition between prey and predator of a partial barrier (structure or space) or by hyperparasitization, and indirectly by an ecologically incomplete relation consisting of either an asynchronous predator-searching and prey-susceptibility relation, or of differential habitation.

In the laboratory, needed protection can be obtained readily by means of partial barriers either obstructional or spatial that form areas of refuge. Such protection is not absolute if it is subject to conditioning by the movement of the prey in and out of the predator's area of search.

In California the cottony cushion scale, Icerya purchasi Mask., is under regulation by the natural enemies, the coccinellid Rodolia cardinalis (Muls.) and the agromyzid Cryptochaetum iceryae (Will.). Because of its dispersion (Smith, 1939), the scale is spatially afforded "threshold" protection without which it either would be regulated by its food supply or exterminated by its natural enemies. [Nicholson (1957) has pointed out that spatial protection is the equivalent of having refuges.]

In a similar manner, the soft scale, Coccus hesperidum L., is given spatial protection from its regulatory natural enemy Metaphycus luteolus (Timb.). Timberlake (1913) noted that "As the soft scale, like most Coccidae, is essentially gregarious in habit, we are led to believe that whenever it is found scattered by ones or twos over the foliage of its host plant, this condition is due to, and is characteristic of, heavy parasitism."

In south China where populations of citrus-infesting red scale, Aonidiella aurantii (Mask.), apparently are under regulation by natural enemies, artificial field infestations of red scale demonstrated that a single citrus leaf, if tightly curled, could afford the scale "threshold" protection (Flanders and Gressitt, 1958).

In Colombia, South America, the populations of the honeydew-feeding ant Rhizomyrna fuhrmanni Forel appear to be under regulation by predatory ants (Solenopsis, Pheidole, etc.). Such regulative action is possible because a $R$. fuhrmanni population, while insuring its survival by constructing a highly cryptic nest in heavy clay, is exposed to attack through the periodic emigrations of its colony-founding queens. $R$. fuhrmanni subsists only on the root-feeding coccid Chavezia caldasiae Bala, whose numbers and honeydew production it adjusts to its nutritional needs (Flanders, 1957).

A classic example of the near, if not actual, extermination of an insect species from a region because of lack of protection from an effective natural 
enemy is that of the nigra scale, Saissetia nigra (Nietn.), a former serious pest of ornamental plants in California. This extermination occurred during the 20-year period following the importation and release in 1937 of the parasite Metaphycus helvolus Comp. The nigra scale, a monovoltine species, lacked spatial protection from $\boldsymbol{M}$. helvolus because of the presence of other host species $[S$. oleae (Bernard) and $S$. hemisphaerica (Targioni-Tozzetti)], which are polyvoltine. These hosts, presumably because of their seasonal distribution, maintain a relatively high population of $M$. helvolus in and around the areas which are habitable for $S$. nigra (Flanders, 1959b).

Protection is absolute when the habitat of the prey includes areas inaccessible to the predator and from which only the surplus prey move into the predator's area of search. This has been demonstrated with underground infestations of the mealybug Phenococcus solani Ferris and the chalcid Acerophagus pallidus Timb. (Flanders, 1944).

Too much protection (above-threshold protection) may preclude economic prey regulation by predators. This may be counteracted by the employment of "foster" hosts. Such host employment has been recommended (Flanders, 1949) when the seasonal scarcity (dispersion in time) of the scale pest (Saissetia oleae) temporarily precludes the regulative action of its natural enemies.

A laboratory population may reach the limiting density and maintain itself near that level for some time if there is little or no delay in the reactions of the limiting factors and there is an adequate food supply and steady physical conditions (Solomon, 1949). However, with such populations the interpretation of fluctuations is still a subject of controversy (Varley, 1960).

Laboratory ecosystems can be arranged so that without the emigration and immigration characteristics of natural ecosystems the phytophagous populations are subject to density-governing factors such as food-depletion or predation, all density independent mortality factors being absent. Woodworth (1908), in discussing parasitic control of insect pests, stated that "The various causes of death may be classed in two groups; first, those that destroy all insects in a certain condition or position irrespective of the numbers present (for instance, frost which might kill the same proportion whether there was but one to the acre or a hundred thousand); and second, those that are more and more efficient as the numbers increase." $\mathrm{He}$ pointed out that the second characteristic "... is true in general of predaceous and parasitic insects and diseases," the efficiency of which "is attested by the approximate balance maintained in nature."

The simplest ecosystem from the standpoint of plant material needed is one with a "food chain" consisting of a measured amount of standardized nonliving plant material, a phytophagous insect, and a predatory insect. As Chapman (1927) suggested, a study of such a relation may lead to a better understanding of the conditions of equilibrium in nature.

\section{THE ANAGASTA ECOSYSTEM}

The population dynamics exhibited by continuous prey-predator systems have been under investigation in the laboratory. of the University of California at Riverside since July, 1956. During this period, 17 such ecosystems have been established (table 1). To date,
10 have been operating with all populations in continuous equilibrium under uniform conditions of temperature and space. The relative humidities ranged from 50 to 80 per cent.

This study, unlike previously reported studies of prey-predator inter- 


\section{TABLE 1}

VITAL STATISTICS OF THE 17 ECOSYSTEMS

(The present procedure in handling the various ecosystems evolved gradually as the wheatprey-predator relationship became apparent and the number of ecosystems increased to 17) The critical importance of the host-habitat configuration and the degree of host protection did not become apparent until the original ecosystem had been in operation for about three years.

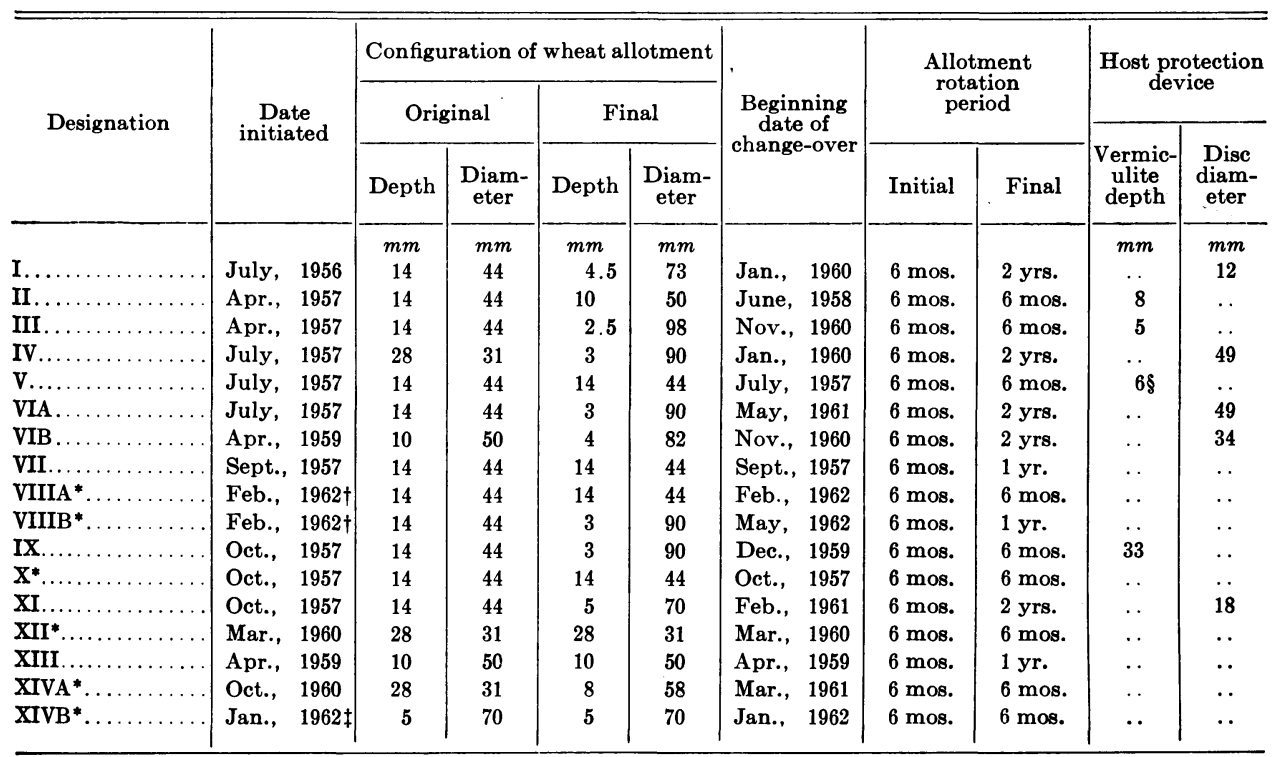

* Exidechthis absent.

Initiated with 24 fresh allotments (12 removed within 2 months) and 1 Anagasta. Original VIII discarded.

Initiated with 12 allotments from XIVA.

$\$$ Vermiculite impregnated with 6 per cent Aramite in acetone beginning November, 1962.

actions, is not limited to the effects of such interactions on the growth and decline of discrete populations as such, being primarily concerned with the stability of ecosystems. Each ecosystem under study consists of a succession of episodes in each of which population generations are more or less discrete. The succession of episodes is so arranged that the generations overlap.

The general objective of this investigation is to ascertain the factors determining the annual equilibrium position of an ecosystem, that is, the level at which mean numerical stability occurs in the ecosystem as a whole, and the departures (oscillations, fluctuations, and outbreaks) from that equilibrium position.

The basic food chain in the ecosystems under investigation consists of sterilized whole wheat processed to form flakes by the Fisher Flouring Mill Co. of Seattle,
Washington (trade name Zoom), and the moth Anagasta kühniella (Zell.). Added to this chain in most of the ecosystems are the egg-feeding mite Blattisocius tarsalis (Berlese) and/or the wasp Exidechthis canescens (Grav.), endoparasitic in the moth larvae (fig. 1).

The significant behavior characteristics of Anagasta, Blattisocius, and Exidechthis, which render them suitable for demonstrating self-perpetuating, persistent, and self-regulating populations, are in part as follows:

\section{Anagasta}

(1) Normal bisexual reproduction on processed whole wheat. (2) A life-cycle ranging from 41 to 106 days at a temperature of $27^{\circ} \mathrm{C}$. (3) The deposition by the adult unfed female, during its life of 5 days, of more than the replacement number of eggs. (4) Continuous 


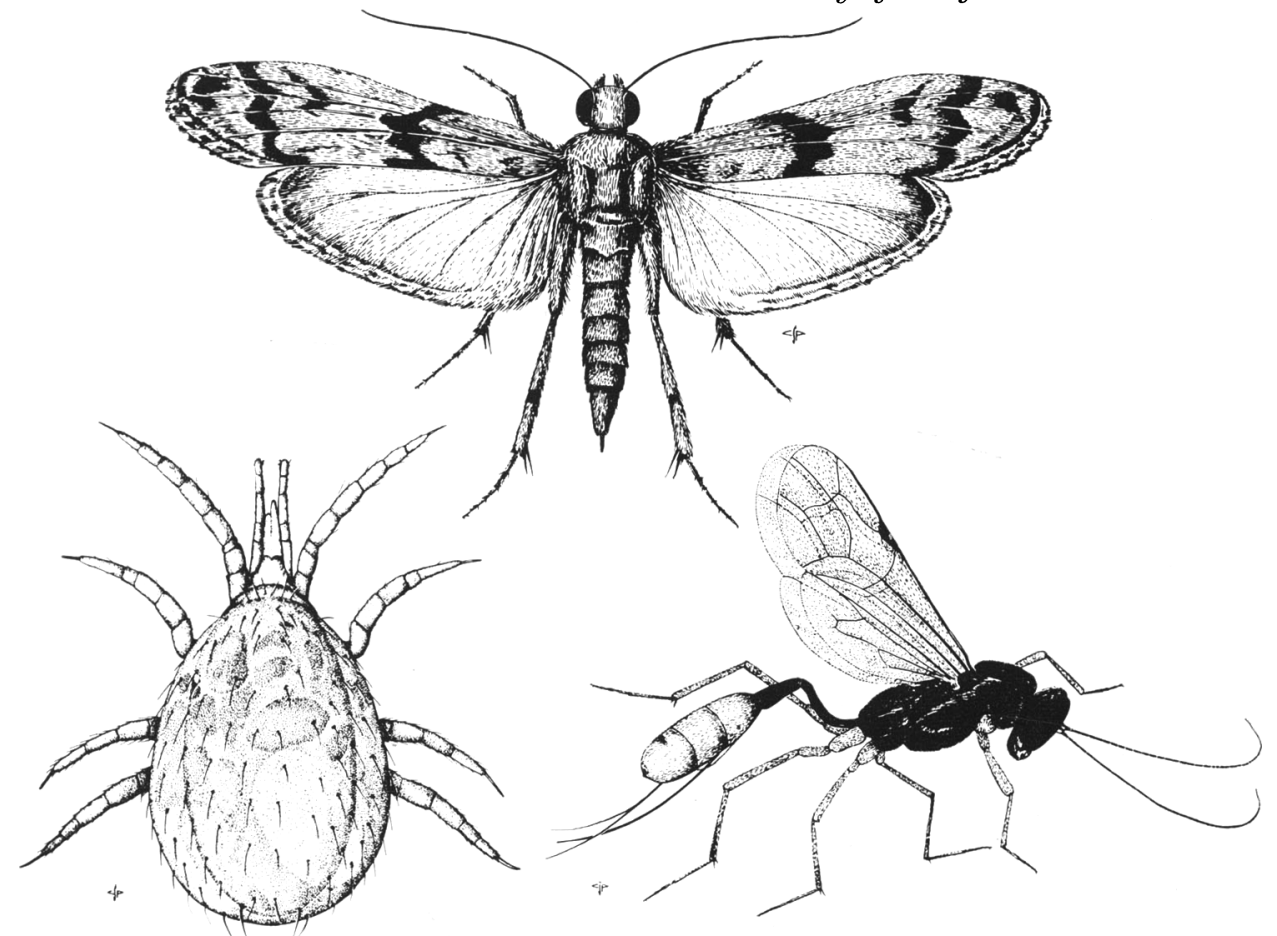

Fig. 1. Depiction of the ecosystem animals: the flour moth, Anagasta kühniella (Zell.), maximum body length about $9 \mathrm{~mm}$; the oophagus mite, Blattisocius tarsalis (Berlese), maximum body length about $0.8 \mathrm{~mm}$; and the endoparasitic wasp Exidechthis canescens (Grav.), maximum body length about $9 \mathrm{~mm}$.

reproduction under laboratory conditions, characterized by the overlapping of generations. (5) Internecine action which, in the absence of regulative natural enemies, eliminates the surplus larval progeny of each generation prior to feeding, a surplus consisting of something less than 99 per cent (Solomon, 1947).

\section{Blattisocius}

(1) Normal bisexual reproduction on Anagasta eggs. (2) A life-cycle (egg to egg) of about 10 days at $27^{\circ} \mathrm{C}$. (3) An adult life of about 10 days. (4) Dispersion by phoresy on the adult Anagasta enhancing a high prey-searching capacity. (5) The prey egg is exposed to attack for 3 days. The larva escapes by burrowing. (6) One Blattisocius necessarily consumes several prey individuals.

\section{Exidechthis}

(1) Normal thelyotokous reproduc- tion on the larvae and pupae of $A n a$ gasta. (2) A life cycle ranging from 21 to 33 days at a temperature of $27^{\circ} \mathrm{C}$. (3) The deposition by the adult unfed female during its life (3 days) of more than the replacement number of eggs. (4) Oviposits in all larval instars of the prey, including the cocooned stages. (5) Only one Exidechthis larva emerges from one prey larva, this occurring after both are full-fed. (6) A prey-finding capacity that enables a population to eliminate an Anagasta population when all the Anagasta larvae are continuously at levels within the reach of the ovipositor.

\section{THE PHYSICAL ENVIRONMENT}

The structure of the Anagasta ecosystems and the manner in which each was initiated has been previously described (Flanders, 1958). Each of the 
established Anagasta ecosystems is an environment delimited by wood, cloth, and glass, a definitive physico-chemical system spatially consisting of 0.13 of a cubic meter ( $4 \frac{1}{2}$ cubic feet). The ecosystems occupy a room (fig. 2) in which the temperature is $27^{\circ} \mathrm{C} \pm 1^{\circ}$ and the relative humidity generally about 55 per cent but ranging up to 80 per cent.

The wheat supply of each ecosystem is introduced periodically in allotments consisting of 120 (7.77 grams) grains in open glass or plastic containers. The wheat in each allotment is lightly tamped to render the surface smooth and level. These allotments, numbering 24 per ecosystem at all times, are introduced in sequence and spaced equally apart in time (either weekly, fortnightly, or monthly) and in position $(11 \mathrm{~cm}$ allotment center to allotment center on the ecosystem floor) in the following pattern:

$\begin{array}{rrrrrr}18 & 12 & 6 & 22 & 2 & 19 \\ 3 & 21 & 17 & 9 & 13 & 7 \\ 14 & 8 & 24 & 4 & 23 & 10 \\ 5 & 11 & 16 & 20 & 1 & 15\end{array}$

By this arrangement the population is presumed to be spatially most uniform in age distribution. The placement of the wheat as discrete allotments simulates natural conditions by causing the grouping of the organisms to form episodes, such episodes (fragmented populations) being the rule in nature (Allee, et al., 1949).

Each of the first 14 ecosystems established was initiated with a single allotment, the additional allotments being added at the rate of one per week. One gravid Anagasta female was introduced with the first allotment. If the food chain was to include Exidechthis, one female was introduced with the third allotment. Each of these animal additions, upon dying, was replaced until its progeny became reproductive.

All the ecosystem populations attained equilibrium positions in which deaths equalled births within six months after their initiation. No live organisms were added or subtracted after the establishment of the desired equilibrium position.

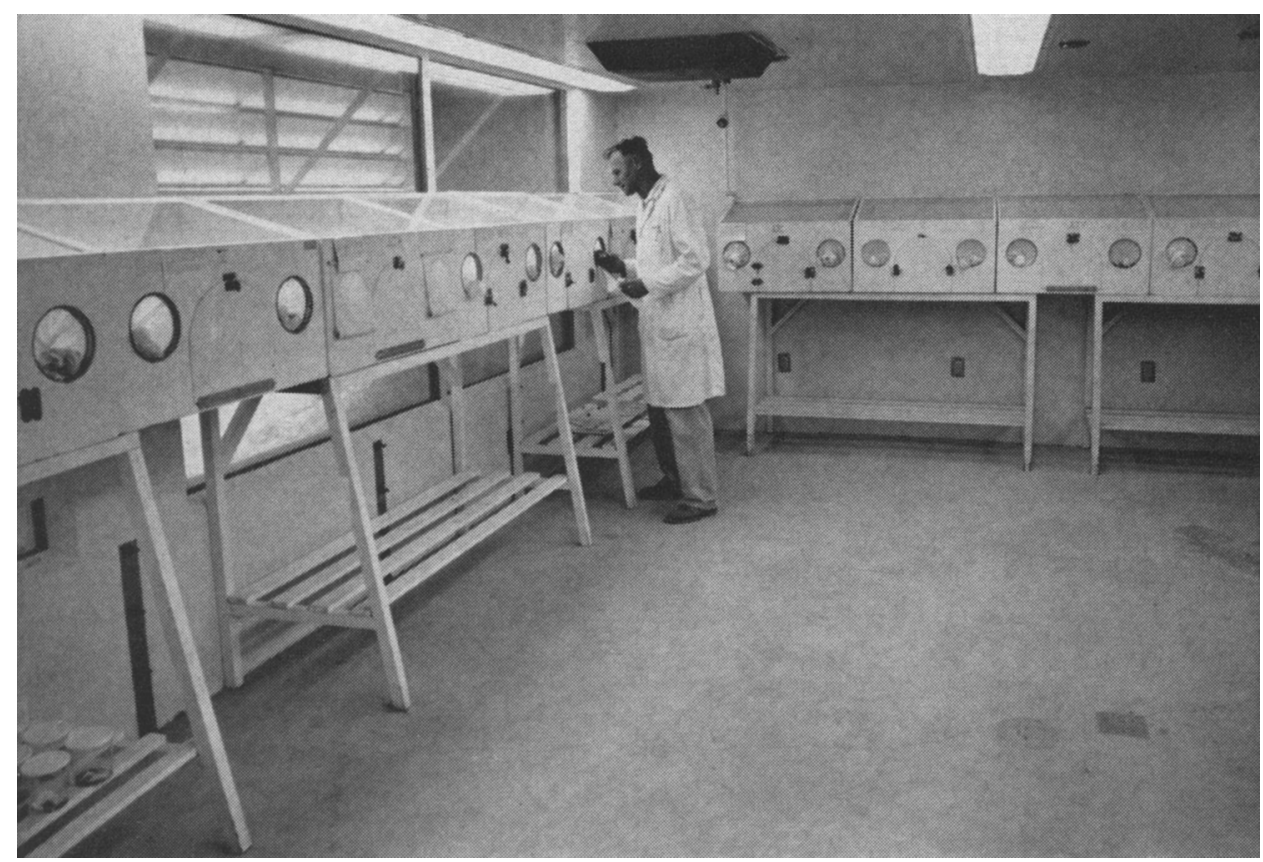

Fig. 2. Photograph of the housing of the Anagasta ecosystems at the University of California Biological Control Laboratory. 
To date, environmental conditions in all ecosystems of space, temperature, and humidity have been maintained practically constant. Illumination which consists of indirect sunlight is not manipulated since the reproduction of the ecosystem's organisms suffers no handicap from it. (Egg deposition by Anagasta is nocturnal and the emergence of Exidechthis is diurnal.)

The census of population is readily taken in the Anagasta ecosystem. This is done each day by ascertaining the numbers of dead adults of Anagasta and of Exidechthis. The status of the Blattisocius populations is ascertained by counting periodically the number of individual Blattisocius carried by the average adult Anagasta at any one time. These, after being shaken from the moth sample, are returned to the ecosystem.

Two or more times a year, depending on the daily abundance of adult $A n a$ gasta, the Anagasta debris is removed from the ecosystem floors. This debris consists of cuticular scales shed by the adult and silken threads deposited by roaming larvae.

In any particular ecosystem all fresh allotments are identical, quantitatively and qualitatively. The areas of discovery by natural enemies are limited to the allotments because they constitute the only areas in which Anagasta's susceptible stages, the egg and the larva, develop.

In certain ecosystems the favorable habitat is enlarged by superimposing upon the wheat a layer of vermiculite (expanded mica of the "Zonolite" type used for agricultural purposes) (Flanders, 1959a). The Anagasta larvae readily inhabit the vermiculite, moving among the particles (which range in diameter from 1 to $3 \mathrm{~mm}$ ) as readily as they do among those of the wheat. However, when the depth of the overlying vermiculite is $90 \mathrm{~mm}$ or more, few, if any, Anagasta larvae are able to reach the wheat. (Table 2.)

In the Anagasta ecosystem, as in nature, the key to "wild life abundance" is the maintenance of proper habitats (Lauckhart, 1962).

\section{HABITAT BIO-FACTS}

The suitability of the Anagasta ecosystem for demonstrating prey-predator interactions is largely dependent on the fact that the principal extrinsic $A n a$ gasta mortality factors operate only within the allotment habitats, these factors being: (1) egg-eating by Blattisocius, (2) internecine (territorial) action of newly-hatched larvae (larval cannibalism, if any, is a negligible factor), and (3) parasitization by $E x$ idechthis.

An important attribute is the habit of the parent organisms of distributing their progeny among the allotment habitats more or less generally at all times. Reproduction of all ecosystem organisms is limited naturally to the equally-spaced allotment-habitats.

The movement of organisms from one allotment habitat to another is almost entirely limited to the adults of $A n a$ gasta, the adults of Exidechthis, and the nymphs and adults of Blattisocius.

The generations of Anagasta occurring in each allotment habitat (episode) are discontinuous, but for the ecosystem as a whole they are continuous. The method of allotment replacement results in the continuous overlapping of the various stages of the successive Anagasta generations, all being present at the same time. The age structure of the Anagasta population tends to be static.

The number of generations per allotment varies inversely with the rate at which the wheat is consumed, i.e. the more rapid the consumption, the fewer the gen $€$ rations. The residue from 120 grains of wheat in completely utilized allotments weighs about 30 grains, including cast skins and fecal material but not cocoons.

Currently the wheat allotments are introduced at the rate of one per week, one per fortnight or one per month, depending on the rate at which the wheat 
TABLE 2

REPRODUCTION OF ANAGASTA IN ECOSYSTEM IX DURING THE 2-YEAR PERIOD ENDING SEPTEMBER 30, 1961 AS INFLUENCED BY THE DEPTH OF THE VERMICULITE COVER BASED ON ADULT MORTALITY ASCERTAINED DAILY

(Vermiculite $90 \mathrm{~mm}$ deep over wheat allotments $14 \mathrm{~mm}$ in depth and $44 \mathrm{~mm}$ in width in effect October, 1959 to March, 1960. Vermiculite $25 \mathrm{~mm}$ deep over wheat allotments $3 \mathrm{~mm}$ in depth and $90 \mathrm{~mm}$ in width in effect March, 1960 to September, 1961.)

\begin{tabular}{|c|c|c|c|c|}
\hline Month & $\begin{array}{c}\text { Full-fed } \\
\text { larvae }\end{array}$ & $\begin{array}{l}\text { Per cent } \\
\text { parasitized }\end{array}$ & $\begin{array}{c}\text { Adult } \\
\text { Anagasta }\end{array}$ & $\begin{array}{l}\text { Range in number } \\
\text { of larvae } \\
\text { becoming full- } \\
\text { fed per day* }\end{array}$ \\
\hline Oct. $1959 \ldots \ldots \ldots \ldots \ldots \ldots \ldots \ldots \ldots \ldots \ldots$ & 264 & 37.12 & 166 & 2 to 19 \\
\hline 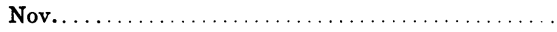 & 193 & 33.16 & 129 & 1 to 13 \\
\hline 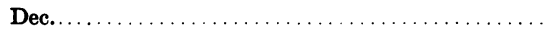 & 131 & 24.50 & 99 & 0 to 11 \\
\hline Jan. $1960 \ldots \ldots \ldots \ldots \ldots \ldots \ldots \ldots \ldots \ldots$ & 65 & 16.92 & 54 & 0 to 8 \\
\hline Feb............. & 46 & 3.44 & $42 \dagger$ & 0 to 7 \\
\hline 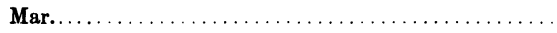 & 123 & $0 \ddagger$ & 123 & 1 to 10 \\
\hline 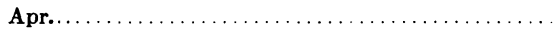 & 129 & 1.55 & 127 & 1 to 7 \\
\hline May $\ldots \ldots \ldots \ldots \ldots \ldots \ldots$ & 143 & 2.79 & 139 & 1 to 10 \\
\hline June................ & 195 & 2.05 & 191 & 2 to 12 \\
\hline July . . . . . . . . . . & 143 & 0.69 & 142 & 1 to 10 \\
\hline Aug............... & 155 & $0 \S$ & 155 & 2 to 9 \\
\hline Sept................ & 136 & 0 & 136 & 0 to 9 \\
\hline Oct........ & 202 & 0 & 202 & 1 to 15 \\
\hline Nov........... & 290 & 0 & 290 & 4 to 20 \\
\hline Dec........ . . . . & 224 & 0 & 224 & 3 to 21 \\
\hline Jan. $1961 \ldots \ldots \ldots$ & 196 & 9.69 & 177 & 2 to 14 \\
\hline Feb......... & 97 & 11.3 & 86 & 0 to 7 \\
\hline Mar..... & 106 & 7.5 & 98 & 0 to 9 \\
\hline Apr..... & 102 & 2.0 & 100 & 0 to 8 \\
\hline May......... & 225 & 0.004 & 224 & 3 to 17 \\
\hline June.... & 295 & 4.40 & 282 & 3 to 17 \\
\hline July..... & 400 & 2.25 & 391 & 6 to 23 \\
\hline Aug............. & 218 & 4.50 & 208 & 3 to 13 \\
\hline 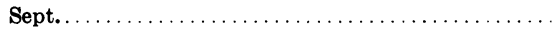 & 276 & 5.00 & 263 & 2 to 16 \\
\hline
\end{tabular}

* Maximum range exhibited in Ecosystem IX without vermiculite $=1-31$.

$\dagger$ Added 70 adult Anagasta to ecosystem.

$\$$ Added 7 parasites to ecosystem.

$\$$ Added 13 parasites to ecosystem.

supply is utilized, this in turn depending on the factor governing the population density (amount of wheat, predation or parasitization).

The rotation period, i.e. the period required for the replacement of 24 allotments, is arbitrarily set for 6 months when each wheat allotment is completely consumed within 6 months; for 1 year when each wheat allotment is not completely consumed until about 10 months old; and for 2 years when a wheat allotment is not completely consumed within 24 months. Since each ecosystem is composed of 24 allotments at all times, a 6 month rotation period requires weekly replacements; a rotation period of a year, fortnightly replacements; and a 2year rotation period, monthly replacements (table 3 ).
The prolongation of the rotation period, being based on the conservation of wheat through Anagasta regulation by natural enemies, is a measure of the efficiency of such enemies. The amount of wheat unused relative to that required to replenish the 24 allotments of an ecosystem is at all times as follows: approximately 30 per cent when the allotment rotation period is 6 months, 50 per cent when this period is 1 year, and 60 per cent when the period is 2 years.

In the absence of natural enemies, the Anagasta larvae completely consume the wheat within the average allotment habitat in 9 weeks. When natural enemies are present and rendered nonregulative by a layer of vermiculite, the complete consumption of the wheat requires 
TABLE 3

PRESENT SCHEDULE OF HABITAT-ALLOTMENT REPLACEMENTS

(Each with 120 grains wheat)

\begin{tabular}{|c|c|c|c|}
\hline Periodicity & Ecosystem & Protective device & Container type \\
\hline Weekly & $\begin{array}{l}\mathrm{II}^{*} \\
\mathrm{III}^{*} \\
\mathrm{~V}^{*} \\
\mathrm{VIIIA}^{*} \\
\mathrm{IX}^{*} \\
\mathrm{X}^{*} \\
\mathrm{XII}^{*} \\
\text { XIVA* } \\
\text { XIVB } \ddagger\end{array}$ & $\begin{array}{l}24 \text { grains vermiculite } \\
48 \text { grains vermiculite } \\
24 \text { grains vermiculite impregnated with ara- } \\
\text { mite } \\
\text { Kelthane pads under allotment containers } \\
336 \text { grains ( } 14 \text { dwt.) vermiculite } \\
\text { None (deep wheat) } \\
\text { None (deep wheat) } \\
\text { None (shallow wheat) } \\
\text { None (shallow wheat) }\end{array}$ & $\begin{array}{l}\text { Small jar, } 50 \mathrm{~mm} \times 40 \mathrm{~mm} \\
\text { Petri dish cover, } 98 \mathrm{~mm} \times 20 \mathrm{~mm} \\
\text { Stender dish with extension ring, } 44 \mathrm{~mm} \times \\
40 \mathrm{~mm} \\
\text { Stender dish, } 44 \mathrm{~mm} \times 23 \mathrm{~mm} \\
\text { Bottom section of quart jar, } 90 \mathrm{~mm} \times 38 \mathrm{~mm} \\
\text { Stender dish, } 44 \mathrm{~mm} \times 23 \mathrm{~mm} \\
\text { Beaker } 30 \mathrm{ml}, 32 \mathrm{~mm} \times 52 \mathrm{~mm} \\
\text { Petri dish top, } 57 \mathrm{~mm} \times 15 \mathrm{~mm} \\
\text { Plastic dish, } 70 \mathrm{~mm} \times 16 \mathrm{~mm}\end{array}$ \\
\hline Fortnightly & $\begin{array}{l}\text { VII } † \\
\text { XIII } † \\
\text { VIIIB } †\end{array}$ & $\begin{array}{l}\text { None (deep wheat) } \\
\text { None (deep wheat) } \\
\text { None (shallow wheat) }\end{array}$ & $\begin{array}{l}\text { Stender dish, } 44 \mathrm{~mm} \times 23 \mathrm{~mm} \\
\text { Petri dish bottom, } 50 \mathrm{~mm} \times 15 \mathrm{~mm} \\
\text { Petri dish bottom, } 90 \mathrm{~mm} \times 22 \mathrm{~mm}\end{array}$ \\
\hline Monthly & 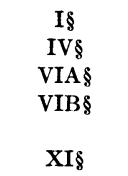 & $\begin{array}{l}12 \mathrm{~mm} \text { cover glass } \\
49 \mathrm{~mm} \text { cardboard cover } \\
49 \mathrm{~mm} \text { cardboard cover } \\
34 \mathrm{~mm} \text { cardboard cover } \\
18 \mathrm{~mm} \text { cover glass }\end{array}$ & $\begin{array}{l}\text { Bakelite jar lid, } 73 \mathrm{~mm} \times 10 \mathrm{~mm} \\
\text { Petri dish bottom, } 90 \mathrm{~mm} \times 22 \mathrm{~mm} \\
\text { Petri dish bottom, } 90 \mathrm{~mm} \times 22 \mathrm{~mm} \\
\text { Plastic thermos bottom section, } 83 \mathrm{~mm} \times \\
18 \mathrm{~mm} \\
\text { Plastic dish, } 70 \mathrm{~mm} \times 16 \mathrm{~mm}\end{array}$ \\
\hline
\end{tabular}

* Under regulation by wheat.

† Under regulation by Blattisocius in conjunction with Exidechthis.

$\ddagger$ Under regulation by Blattisocius alone.

$\$$ Under regulation by Exidechthis alone.

an additional 1 or 2 weeks. When natural enemies are present and preyregulative, the complete consumption of wheat requires from 3 to 30 months, depending on the degree to which the prey are protected from natural enemy attack.

When population abundance is regulated by Exidechthis as in Ecosystem I,

\section{A B}

Final weight

Population yield:
Adult Exidechthis
Adult Anagasta
$=60$
$=6$

Several representative 2-year-old undepleted allotments taken from Ecosystem I during late 1962 and early 1963

Single
allotment

Final weight

August

Population yield:

$\begin{array}{lr}\text { Adult Exidechthis } & 50 \\ \text { Parasitized larvae } & 14 \\ \text { Adult Anagasta } & 0\end{array}$

each allotment, although not completely depleted, is replaced at the end of 2 years.

Four representative 6-month-old wheat-depleted allotments taken from Ecosystem I during 1958 when the wheat supply was Anagasta-regulative, were analyzed as shown below.

B

C

D

37 grains $\quad 37.5$ grains 37.5 grains

70

73

8

74

4

when Exidechthis was Anagasta-regulative, were analyzed as shown below.

$\begin{array}{ccc}\begin{array}{c}\text { Single } \\ \text { allotment } \\ \text { July }\end{array} & \begin{array}{c}\text { Average } \\ \text { of } 4 \\ \text { allotments }\end{array} & \begin{array}{c}\text { Average } \\ \text { of } 8 \\ \text { allotments }\end{array} \\ \begin{array}{r}48 \text { grains } \\ 9 \text { grains }\end{array} & \begin{array}{c}50 \text { grains } \\ 13 \text { grains }\end{array} & \begin{array}{c}51 \text { grains } \\ 16 \text { grains }\end{array}\end{array}$

$\begin{array}{rrr}60 & 59 & 68 \\ 9 & 11 & 6 \\ 10 & 3 & 2\end{array}$


The total number of Anagasta eggs deposited on each allotment of wheat is greatly in excess of the number of larvae that can become full-fed upon it. This is indicated by the facts that (1) the number of full-fed larvae per wheat allotment increases with the percentage of parasitization, provided that the annual percentage of parasitization does not exceed about 80 (Flanders and Badgley, 1960), parasitized larvae attaining maturity on less food than unparasitized larvae (the average number of full-fed larvae per allotment ranges from about 60 when unparasitized to about 90 when parasitized); (2) in the presence of a bacterial epizootic which destroys up to 90 per cent of all the feeding larvae, the wheat may be completely utilized so rapidly that the rotation period for the 24 allotments may be decreased from 6 to 2 months. This occurred in Ecosystem XIVA during July, August, and September, 1961.

The authors have determined experimentally that when a number $(50 \pm)$ of newly-hatched Anagasta larvae are within a given area $(80 \mathrm{~mm}$ or less in diameter), the amount of available wheat may determine the per cent of internecine mortality prior to feeding. All larvae but one are destroyed by internecine action soon after hatching, if the amount of food is merely sufficient for the first instar development of a single larva. Consequently, as a rule, the greater the distribution (dispersal) of the given amount of wheat (120 grains) available to first instar populations, the less internecine action, the greater the number of initial survivors, and conse.quently the more rapid the consumption of wheat. This was demonstrated during the development of Ecosystems VIIIA and VIIIB. In VIIIA where the wheat allotments are $44 \mathrm{~mm}$ in diameter, 11 weeks were required for the complete consumption of the wheat; in VIIIB where the wheat allotments are $90 \mathrm{~mm}$ in diameter, only 5 weeks were required. In each instance natural enemies were absent. However, in ecosystems similar to III where the wheat allotments are $98 \mathrm{~mm}$ in diameter and are overlaid with vermiculite less than $5 \mathrm{~mm}$ in depth, the consumption of wheat may be so retarded by the internecine larval mortality supplemented by parasite-caused mortality that several partly grown larvae are usually present at the end of 6 months, sustained by minute amounts of wheat.

The intensity of internecine strife is a function of larval density modified by the amount of inhabited wheat. With a given amount of wheat and natural enemies absent, the greater the number of newly-hatched Anagasta larvae over one per two grains of wheat, the smaller the number that escape starvation and become adult. Larval internecine strife is regulative in the sense that it determines the distribution in time of the larvae that completely consume the available food. However, when the population is parasite-regulated, internecine strife may never occur.

When the natural enemies are present but nonregulative, the internecine action of the Anagasta larvae in conjunction with egg-feeding by Blattisocius so adjusts the numbers of feeding larvae to the food supply that practically all complete their larval development.

The "seeding" of the allotment habitats with eggs by the Anagasta female is more or less continuous, depending upon the daily density of the female adults.

In the Anagasta ecosystem the silken threads spun by the newly-hatched larvae serve not only to bind together all habitat particles but to stimulate oviposition. It has been observed by C. B. Huffaker (personal communication) that Anagasta tends to deposit more eggs on wheat allotments already infested than on fresh allotments.

The establishment of wheat-regulated Anagasta ecosystems that will remain free of disease epizootics requires the introduction of Blattisocius with the initial Anagasta females, the latter being introduced at intervals which insure 
continuity in the availability of the Anagasta eggs needed for Blattisocius reproduction. However, in such ecosystems epizootics of bacterial disease may be induced either by suddenly increasing the wheat supply or by introducing the parasite Exidechthis and arranging the physical environment to render it non-host-regulative. In the first case, a wheat supply suddenly increased to the point where the Anagasta eggs are widely dispersed, may result in the starvation of Blattisocius and the increase of Anagasta larvae to densities conducive to disease epizootics.

In the second case, a similar starvation effect may occur when during periods of low host densities the few full-fed Anagasta larvae vield adult $E x$ idechthis rather than adult Anagasta. In ecosystems in which the Anagasta population is not regulated by natural enemies, each habitat-allotment is characterized by a sequence of two types of intraspecific competition: (1) that of the newly-hatched larvae for space, and (2) that of successive generations of the feeding larvae for a diminishing food supply. (The depletion of the food supply by reducing habitat size intensifies the internecine strife of the newlyhatched larvae). In ecosystems in which the natural enemies are regulative, larval competition, if any, is limited to the avoidance of natural enemy attack. Under ecosystem conditions, the effect of food depletion upon the feeding larvae is usually reduction in size, not starvation.

\section{CRITICAL ABIOTIC FACTORS}

As pointed out in a preliminary note (Flanders, 1958), one of the objectives in the establishment of the Anagasta ecosystems was to analyze and evaluate the role of protection from natural enemies in determining equilibrium positions resulting from prey-predator interaction. In such ecosystems the protection afforded Anagasta by structural or spatial barriers is not absolute, being conditioned by the habits of both prey and predator. Protection can be evaluated only in relation to population survival.

It is generally recognized that some protection of the prey is essential for its continuous regulation by a predator. Solomon (1949) pointed out that the heterogeneity of a natural environment insures that some part will afford protection (refuge) for some of the populations and that the "threshold of security" plays an important part in natural control.

According to Elton (1942) the "carrying capacity of the cover" for mouse-like rodents (voles) is variable because the cover constitutes their food, also. The eating down of the cover automatically increases exposure to predators. A like interaction occasionally occurs in the Anagasta-Exidechthis ecosystem when the eating down of the wheat by $A n a$ gasta larvae increases their exposure to attack by Exidechthis (Flanders and Badgley, 1960).

The area of the ecosystems over which the natural enemies search for their prey is sufficiently large to enable an individual prey, even when continuously vulnerable, to escape any particular individual enemy. The chance of an Anagasta larva escaping attack by $E x$ idechthis increases as the amount of larval spoor (silk threads) accumulates over the allotment surfaces (fig. 3 ). Host-finding by Exidechthis decreases in efficacy as the spoor becomes generally distributed.

The degree of protection determines which of three factors, wheat supply (depletion), predatism or parasitism operates to govern population density. The configuration of the wheat allotment may determine the degree of protection, the consequent internecine mortality of the newly-hatched Anagasta, and the power of discovery of Blattisocius and of Exidechthis.

Wheat allotment configurations are determined by the dimensions of their containers (table 3 and fig. 4). Protection from natural enemy attack, how- 


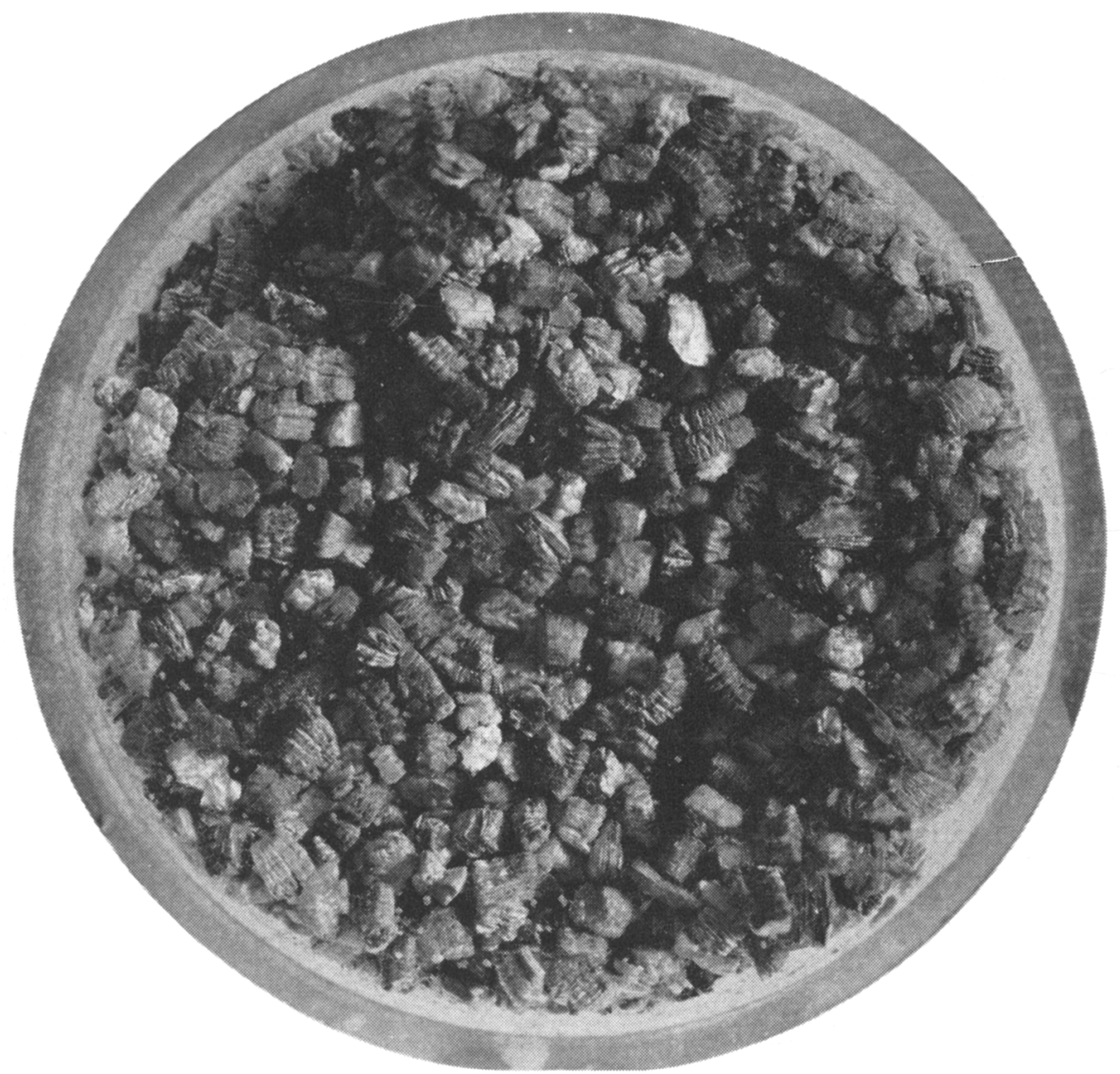

Fig. 3. Eggs of Anagasta strung on strands of larvae-spun webbing that bind together the particles of vermiculite.

ever, can be modified not only by manipulation of the wheat allotment dimensions but by superimposing on each allotment either a layer of vermiculite (Flanders, 1959a) or a disc of glass or cardboard (figs. 5, 6, 7). The protective value of the vermiculite depends upon its depth, that of the disc upon its area and the proportion of the allotment area that it covers. Dises of different areas may have the same degree of protection when superimposed on wheat allotments of different areas.

The 17 Anagasta ecosystems differ abiotically from each other in the dimensions of the wheat allotments, in their rotation periods, and in the superimposed protection devices. However, the elimination of significant predation by Blattisocius may require the addition of chemicals: Aramite-impregnated vermiculite, Tedion dust on the surfaces of wheat allotments, and Kelthane-impregnated pads under the allotment containers (table 3). The phoretic Blattisocius population can be maintained at insignificant levels (an average of 1 Blattisocius to 2 or more Anagasta adults) as was done in Ecosystem VIIIA during the 6-month period ending October 31, 1963. This was accomplished by placing the allotment containers on felt dises impregnated with $10 \%$ Kelthane.

The allotment dimensions and protection devices (barriers) determine the effectiveness in host-finding of the Blattisocius and Exidechthis populations, although the inherent searching capacity of each individual remains unchanged. Physical factors, therefore, 


\section{Sagittal Delineations of 13 Larval Anagasta Habitats}

(Dimensions in Millimeters)

\begin{abstract}
Enemies Present
Blattisocius Exidechthis
\end{abstract}

Exidechthis Blattisocius

Blattisocius

Exidechthis

Exidechthis

Exidechthis

Blattisocius

Blattisocius

Exidechthis

Blattisocius

Exidechthis

None or rare

Blattisocius Exidechthis

Blattisocius Exidechthis

Fig. 4
(III)

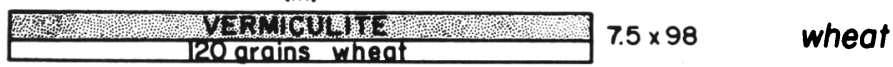

(IX)

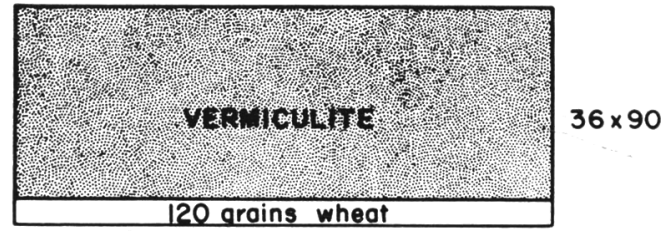

(VIII-B)

120 aroins wheof $3 \times 90$

Blattisocius

(IV)

120 arains wheot $3 \times 90$

Exidechthis Host protected by overlying $49 \mathrm{~mm}$.disc

(Vi-B) 120 groins wheat $4 \times 82$

Exidechthis Host protected by overlying $34 \mathrm{~mm}$. disc

(1) 120 grains wheot
Host protected by overlying $12 \mathrm{~mm}$. disc
$4.5 \times 73 \quad$ Exidechthis \begin{tabular}{c}
$(x \mid V-B)$ \\
\hline 120 groins wheat $5 \times 70 \quad$ Blattisocius
\end{tabular} (XIV-A) 120 grains wheat $8 \times 58 \quad$ wheat

(XIII)

120 groins wheat $10 \times 50 \quad$ Exidechthis

(II)

\begin{tabular}{|c|c|}
\hline VERTICUIII & \\
\hline 120 grains wheat & $18 \times 4$ \\
\hline
\end{tabular}

(v)

\begin{tabular}{|c|c|}
\hline 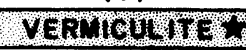 & \\
\hline 120 grains wheat & $20 \times 44$ \\
\hline
\end{tabular}

(VII)

120 grains wheot $14 \times 44 \quad$ Blattisocius

(XII)

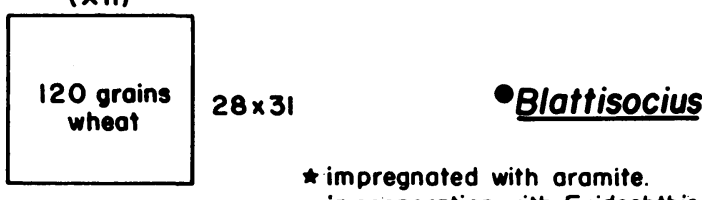

- in cooperation with Exidechthis 


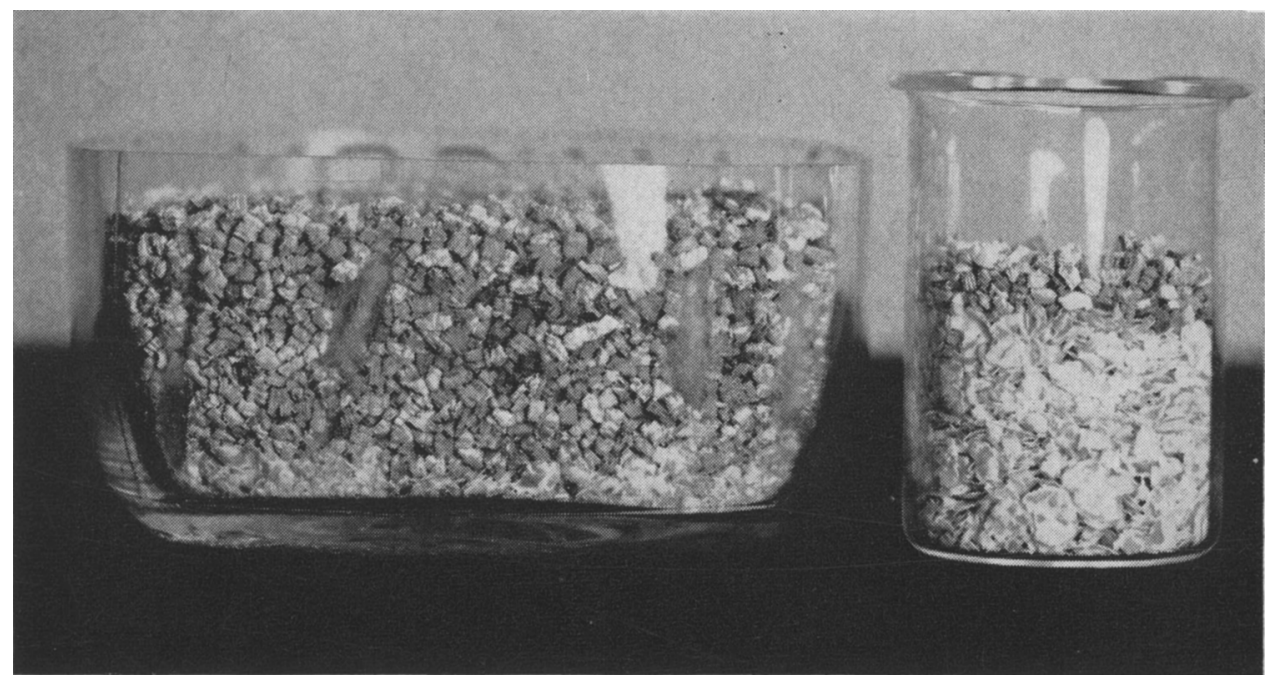

Fig. 5. Photograph of two larval habitats of Anagasta kühniella which have been employed in the Anagasta ecosystems. Left: An allotment of 120 grains of wheat (diameter $90 \mathrm{~mm} \times$ depth $3 \mathrm{~mm}$ ) covered with a vermiculite layer $33 \mathrm{~mm}$ in depth; complete consumption of wheat requires 3 months. Right: An allotment of 120 grains of wheat (diameter $32 \mathrm{~mm} \times$ depth $28 \mathrm{~mm}$ ) covered with a vermiculite layer $6 \mathrm{~mm}$ in depth; complete consumption of wheat may occur in 2 months. The difference in rate of wheat consumption is presumably, in part, an effect of the starvation of newly-hatched Anagasta larvae, an effect which increases with the depth of vermiculite. In ecosystems with such allotments, the equilibrium position is ultimately determined by the amount of wheat regardless of the presence or absence of either Blattisocius or Exidechthis.

may decisively influence the action of biotic factors (Solomon, 1949).

The protective value of refuges is, of course, enhanced by the lack of coordinated searching among the individuals of the natural enemy population. As pointed out 22 years ago by Smith (1939), the efficiency of a predator in regulating the population density of its prey depends upon its power of discovery as well as upon prey availability. Smith concluded that the effectiveness of a predator as a control agency is determined more by its capacity to discover prey in relation to prey density than by any other quality. In the highly restricted Anagasta ecosystems the predator's power of discovery is largely an effect of prey availability.
The Anagasta ecosystems demonstrate the phenomenon that the accessibility of a prey has a density-governing effect on the population of its predators (Latham, 1952), that when healthy prey are readily attacked by predators it is the space property of the food, not nutriment, that is decisive (Nicholson, 1950).

Both Blattisocius and Exidechthis are numerically dependent on prey density whether or not they are prey-regulative. Prey regulation is inhibited when the wheat allotment habitats are enlarged with a cover of vermiculite from $3 \mathrm{~mm}$ to $33 \mathrm{~mm}$ in depth (table 4 ). With this enlargement, the food supply remaining the same, the prey population is decreased in density (although not in total abundance), so that food consumption is

Fig. 4. Habitat-allotment configurations characterizing the Anagasta ecosystems, configurations that by determining which one of the possible regulative factors operate as such, determine the annual populations of full-fed Anagasta larvae.

With wheat the regulative factor, the annual population per ecosystem is $4500 \pm 666$. With Blattisocius plus Exidechthis regulative, the annual population per ecosystem is $2500 \pm 110$.

With Exidechthis alone regulative, the annual population per ecosystem is $1400 \pm 170$. 


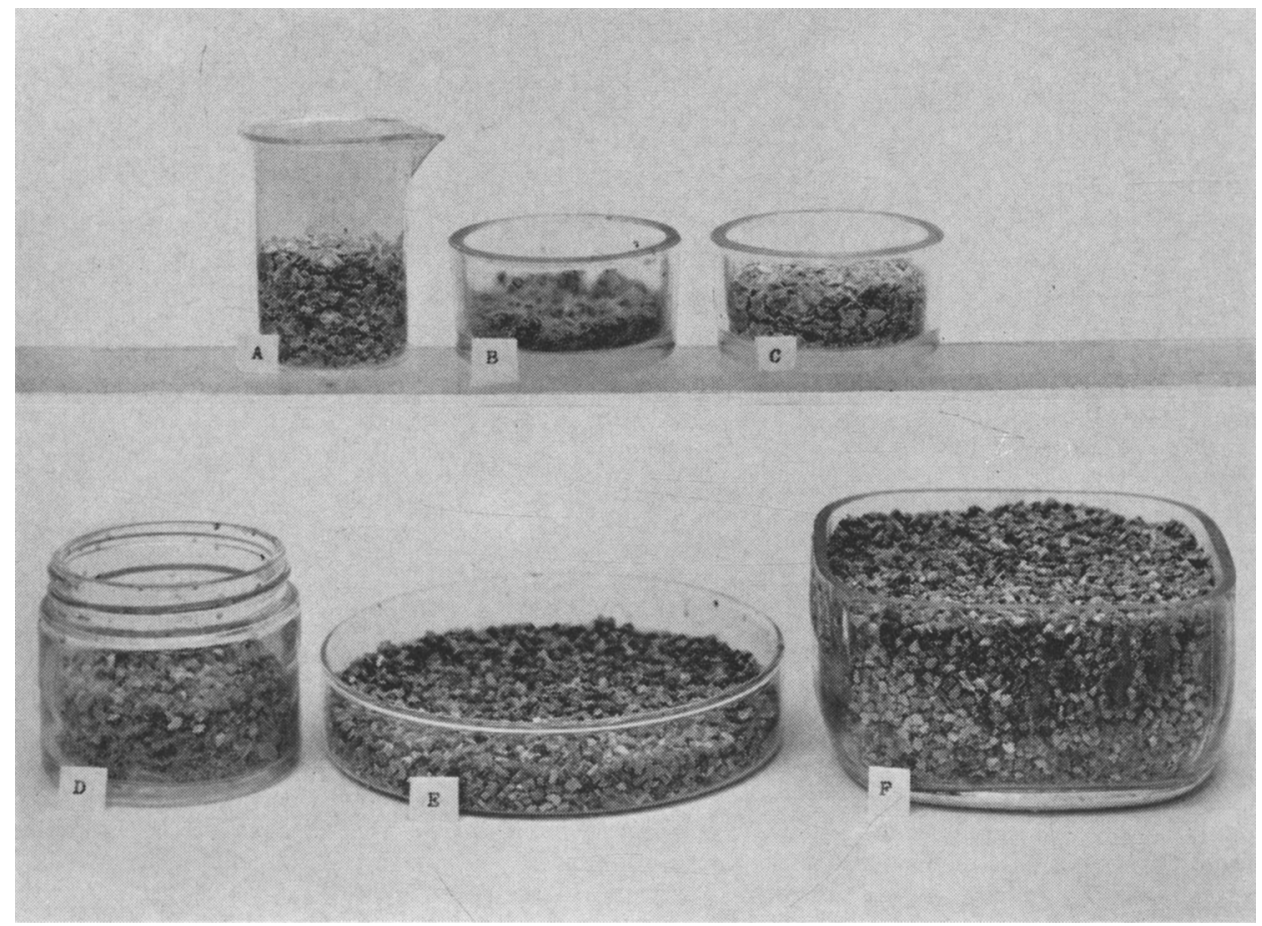

Fig. 6. Photograph of six allotment-habitats from five ecosystems:
A $(32 \mathrm{~mm} \times 28 \mathrm{~mm})$ from Ecosystem XII
B $(44 \mathrm{~mm} \times 14 \mathrm{~mm})$ from Ecosystem $X$
C $(44 \mathrm{~mm} \times 14 \mathrm{~mm})$ from Ecosystem $X$
D $(50 \mathrm{~mm} \times 18 \mathrm{~mm})$ from Ecosystem II
E $(98 \mathrm{~mm} \times 8 \mathrm{~mm})$ from Ecosystem III
$\mathrm{F}(90 \mathrm{~mm} \times 36 \mathrm{~mm})$ from Ecosystem IX

A and $\mathrm{C}$ consist of fresh wheat. The wheat in B, D, E, and F has been completely utilized. The "eating down" of the wheat from that as in $\mathrm{C}$ to that as in B increasingly exposed the larrae therein to attack by Exidechthis.

somewhat prolonged. Under such conditions prey abundance is a function of the food supply, excess prey having been eliminated prior to feeding either by internecine action or by starvation in the search for food. Then the natural enemy attains its greatest abundance, an abundance more or less equal to the superfluity of hosts.

The enlargement of the allotment habitats by the addition of vermiculite (fig. 8) decreased the natural enemy's area of discovery without changing the amount of the prey-supporting medium (Flanders, 1959a). Blattisocius is thus rendered non-prey-regulative, its prey searching capacity being reduced either because of a preference to search the wheat for Anagasta eggs rather than to search the vermiculite, or because a large portion of the eggs is protected by being placed on the silken strands spun by the Anagasta larvae between vermiculite particles.

Exidechthis also is rendered nonprey-regulative by the addition of vermiculite. Its searching capacity is reduced because of the increase in the prey-inhabited area which it is unable to search effectively, this increase enlarging the area beyond the reach of the parasite's ovipositor and reducing the frequency with which the larvae move in and out of the parasite's oviposition range. 


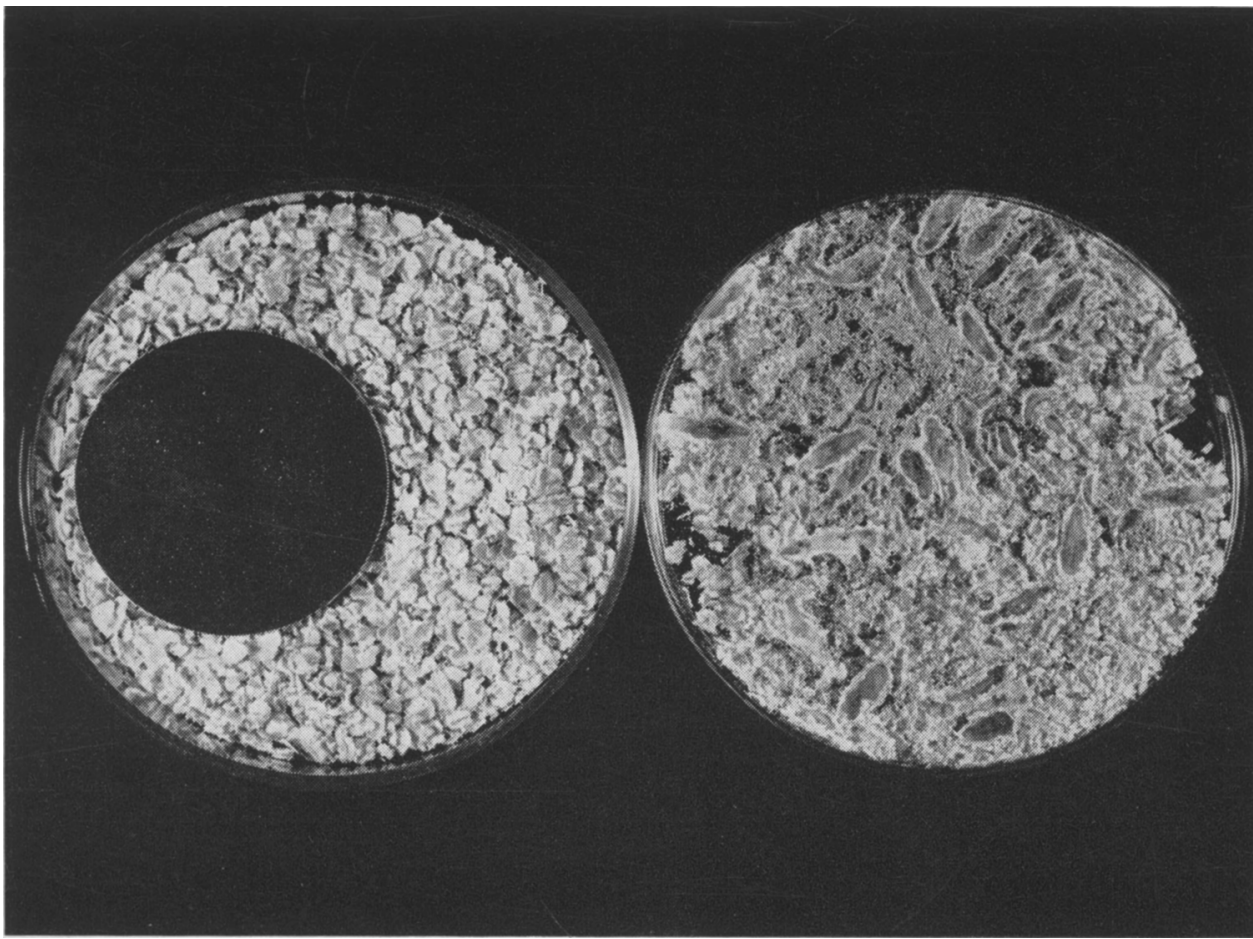

Fig. 7. Photograph of two allotment-habitats in Ecosystem IV; that on the left shows the exposed upper surface of a 3-month-old habitat with a $49 \mathrm{~mm}$ cardboard disc overlying the wheat; that on the right shows the under surface of an 8-month-old habitat and the cocoons of Anagasta largely concentrated under the $49 \mathrm{~mm}$ disc, presumably a thigmotropic response. Most, if not all, of the Anagasta cocoons contain the cocoon of Exidechthis. The $49 \mathrm{~mm}$ disc may permit 3.5 per cent of the annual population of the full-fed Anagasta larvae to become adult.

Under such conditions, the percentage of hosts found annually by Exidechthis varies with the depth of the vermiculite layer superimposed on the wheat allotments, the percentage ranging from about 10 per cent when the vermiculite is $33 \mathrm{~mm}$ in depth to about 80 per cent when it is about $2^{1 / 2} \mathrm{~mm}$ in depth. The effect of lesser variations correlated with habitat allotment diameters is shown in table 5. However, as pointed out by A. J. Nicholson (personal correspondence) a non-regulative natural enemy may act in essentially the same way as a destructive physical factor, the proportion of hosts destroyed not varying with host density.

When allotment habitats consist of vermiculite $33 \mathrm{~mm}$ in depth overlying the wheat, the mortality of the newlyhatched Anagasta larvae may be effected by starvation as well as by internecine action. Anagasta larvae that do not move more or less directly downward may not live long enough to find the supply of wheat. As a consequence, the time required for the consumption of the food supply may be prolonged. In Ecosystem IX, such a delay in the complete consumption of food is correlated with a reduction in competition for the food so that full-fed larvae may attain maximum size and the body lengths of the adults therefrom exceed the average by $1 \mathrm{~mm}$. In an ecosystem such as $\mathrm{V}$, in which food is the governing factor and which is relatively free of natural enemies, competition is such that the adult Anagasta exhibits the maximum variation in over-all length, ranging from 6 $\mathrm{mm}$ to $12 \mathrm{~mm}$. When in an ecosystem such as VIIIB Anagasta is effectively controlled by Blattisocius the adults are consistently of maximum size. 
TABLE 4

TEN ANAGASTA-ROLLED-WHEAT ECOSYSTEMS CLASSIFIED ACCORDING TO THREE DENSITY-CONTROLLING FACTORS AND THE HABITAT CHARACTERISTICS DETERMINING THE OPERATION OF THESE FACTORS

\begin{tabular}{l|c|c|c|c|c|c}
\hline Ecosystem & $\begin{array}{c}\text { Average number of } \\
\text { larvae becoming } \\
\text { full-fed per month }\end{array}$ & $\begin{array}{c}\text { Average per } \\
\text { cent para- } \\
\text { sitization }\end{array}$ & $\begin{array}{c}\text { Habitat } \\
\text { diameter } \\
\text { mm }\end{array}$ & $\begin{array}{c}\text { Habitat } \\
\text { depth } \\
\text { mm }\end{array}$ & $\begin{array}{c}\text { Wheat } \\
\text { depth } \\
\text { mm }\end{array}$ & $\begin{array}{c}\text { Vermiculite } \\
\text { depth } \\
\text { mm }\end{array}$ \\
\hline
\end{tabular}

Population density controlled by the supply of wheat (food depletion). (Regulation of Anagasta populations by either Exidechthis or Blattisocius is inhibited by the vermiculite portion of the habitats)

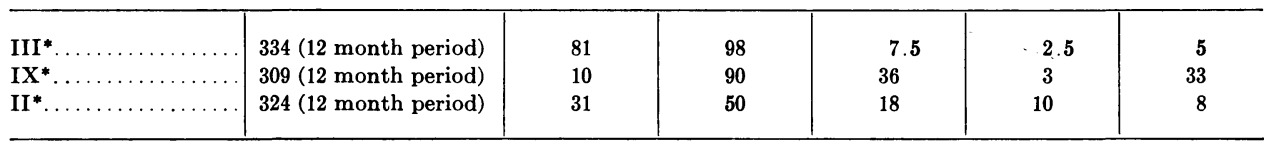

Population density controlled by Blattisocius in cooperation with Exidechthis (a protective layer of vermiculite is lacking).

\begin{tabular}{l|l|l|l|l|l|l}
\hline $\mathrm{X}^{*} \ldots \ldots \ldots \ldots \ldots \ldots \ldots$ & $25 \mathrm{C}(12$ month period $)$ & 34 & 44 & 14 & & $\ldots$ \\
$\mathrm{XII} \ldots \ldots \ldots \ldots \ldots \ldots$ & 243 (12 month period) & 37 & 32 & 28 & $\ldots$ & $\ldots$ \\
\hline
\end{tabular}

Population density controlled by Exidechthis alone (a protective layer of vermiculite is lacking). Exidechthis regulation of Anagasta populations permitted by shallow wheat.

\begin{tabular}{|c|c|c|c|c|c|}
\hline IVt................ & 119 (24 month period) & 98 & 90 & 3 & $\begin{array}{l}\text { Anagasta protected by a } \\
\text { plastic disc } 45 \mathrm{~mm} \text { diam- } \\
\text { eter }\end{array}$ \\
\hline
\end{tabular}

Population density controlled by Blattisocius alone. Blattisocius regulation of Anagasta populations permitted by shallow wheat and lack of Exidechthis.

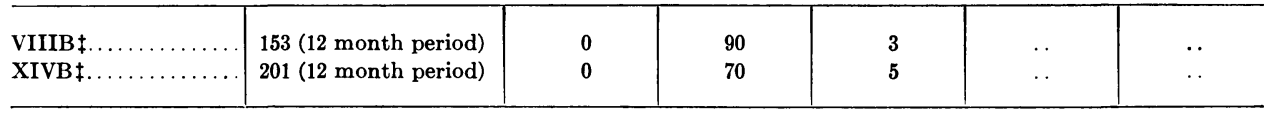

* Blattisocius and Exidechthis present.

$\dagger$ Blattisocius absent.

$\ddagger$ Exidechthis absent.

When the depth of the habitat allotment $(4.5 \mathrm{~mm})$ forces the Anagasta larvae to construct their cocoons horizontally beneath the wheat supply, as in Ecosystem I, the depth of their habitat is increased by $1 \mathrm{~mm}$ or more. Such an increase constitutes a form of self-protection.

\section{BLATTISOCIUS AS A DENSITY-GOVERNING FACTOR}

Blattisocius is generally prey-regulative when the area searched does not greatly exceed the area in which prey can be found and when egg density is such that the spatial protection afforded the eggs is not excessive. The allotment habitats should be removed from the ecosystem before the spoor of Anagasta accumulates to the point that it precludes such regulation.

In Blattisocius-regulated Anagasta ecosystems the equilibrium positions are determined by the intraspecific competition for Anagasta eggs. The intensity of this competition decreases as the spatial protection afforded the prey by the prey's distribution increases. (The "predator" population acting alone, unlike that of the "parasite," rarely, if ever, eliminates its prey. The predator, 


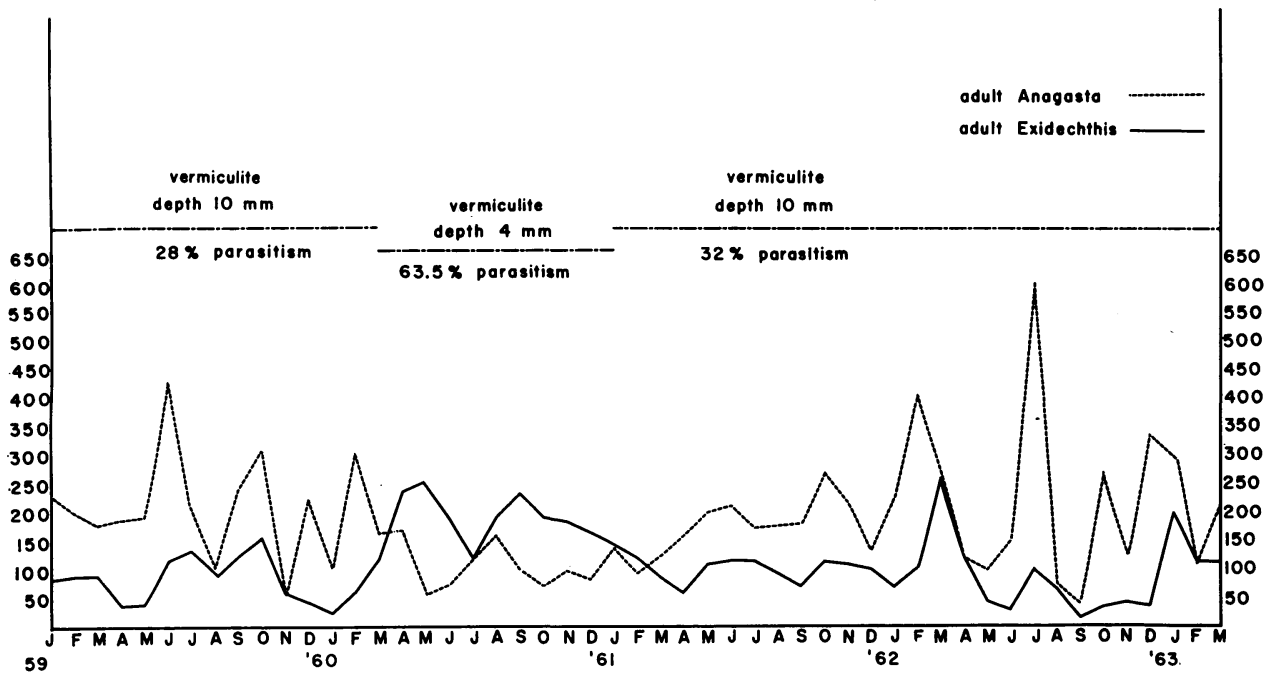

Fig. 8. Graph based on adult mortality of Anagasta and Exidechthis ascertained daily depicting the effect of different depths of vermiculite covering the wheat allotments on the parasitization of Anagasta larvae by Exidechthis in Ecosystem II.

needing more than a single prey individual for survival, is more likely to eliminate itself through over-exploitation of the prey population.)

Prey regulation by Blattisocius alone is precluded when the depth of the wheat exceeds $10 \mathrm{~mm}$ (fig. 9) or when the wheat has a cover of vermiculite, Blattisocius by itself being consistently regulative only at wheat depths between 2 and $8 \mathrm{~mm}$. However, Blattisocius pop- ulations in cooperation with populations of Exidechthis, may be regulative at wheat depths ranging from 10 to $28 \mathrm{~mm}$ as in Ecosystems X and XII.

Prey-regulative efficiency of Blattisocius, as measured by the amount of wheat conservation, is maximum when the wheat depth is $3 \mathrm{~mm}$ as in Ecosystem VIIIB. This maximum is less than that attained in Exidechthis-regulated ecosystems. Either Blattisocius or Exidech-

TABLE 5

\section{COMPOSITION AND DIMENSION OF LARVAL HABITATS IN EACH OF THREE ANAGASTA ECOSYSTEMS AND THE CONSEQUENT HOST SURVIVAL AND PARASITIZATION*}

\begin{tabular}{|c|c|c|c|c|c|}
\hline \multirow{2}{*}{ Ecosystem } & \multirow{2}{*}{$\begin{array}{l}\text { Composition of larval host habitats } \\
\text { in which ecosystem episodes occur }\end{array}$} & \multicolumn{2}{|c|}{$\begin{array}{l}\text { Dimensions in mm of } \\
\text { larval host habitats } \\
\text { exposed to parasite }\end{array}$} & \multirow{2}{*}{$\begin{array}{c}\text { Surviving } \\
\text { adult host } \\
\text { populations } \\
\text { per year }\end{array}$} & \multirow{2}{*}{$\begin{array}{c}\text { Per cent } \\
\text { parasitization } \\
\text { per year based } \\
\text { on annual } \\
\text { populations }\end{array}$} \\
\hline & & Diameter & Depth & & \\
\hline V. & $\begin{array}{l}120 \text { grains of wheat plus cover of ver- } \\
\text { miculite } 6 \mathrm{~mm} \text { deep }\end{array}$ & 44 & 20 & 1,290 & 60 \\
\hline VII. & $\begin{array}{l}120 \text { grains of wheat plus cover of ver- } \\
\text { miculite } 11 \mathrm{~mm} \text { deep }\end{array}$ & 44 & 25 & 2,027 & 40 \\
\hline II... & $\begin{array}{l}120 \text { grains of wheat plus cover of ver- } \\
\text { miculite } 10 \mathrm{~mm} \text { deep }\end{array}$ & 50 & 20 & 3,368 & 31 \\
\hline
\end{tabular}

* Rarefication of a host population to effect a change in equilibrium status is attained by increasing the depth of the larval habitat by the addition of vermiculite.

Data for each ecosystem are based on the 1959 sequences of 52 episodes, each sequence encompassing 9 host generations.

Vermiculite renders. the natural enemies (Blattisocius and Exidechthis) non-regulative. 


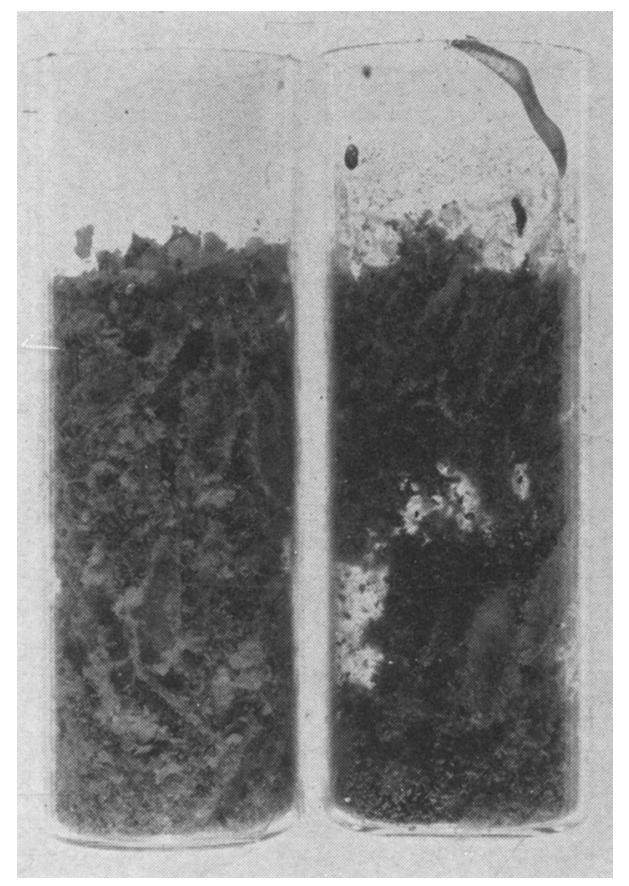

Fig. 9. Wheat allotments when $22 \mathrm{~mm}$ in diameter and $55 \mathrm{~mm}$ in depth render the populations of Anagasta immune from regulation by either Blattisocius or Exidechthis, separately or in cooperation. Wheat in vial at left about $1 / 3$ consumed, that in vial at right completely consumed. Cocoons of early maturing larvae are so concentrated in the top layers of the wheat that a portion of the spoor material is prevented from settling.

this acting alone may limit the full-fed larval population to less than one-third that permitted by the wheat supply.

The efficiency of Blattisocius regulation is largely an effect of two phenomena, the high developmental rate (10day life cycle at $27.5^{\circ} \mathrm{C}$ ) which permits a population increase at the rate of four generations to one of the prey, and the habit of phoresy which ensures contact between the predator and the egg of the prey. (Presumably, the adult Blattisocius leave the bodies of the ovipositing moths only temporarily.)

When a Blattisocius population alone regulates that of Anagasta, the number of individual predators carried about by each Anagasta adult varies from one to 16. The greater the protection afforded the eggs of Anagasta the greater the average number of Blattisocius carried by the Anagasta adult, this average under an allotment rotation period of 1 year being 4.3 in Ecosystem VIIIB and 6.5 in Ecosystem XIVB. (These figures were determined on the basis of 34 consecutive samples taken weekly from each ecosystem, beginning November, 1962.)

The maximum number of Blattisocius observed per adult Anagasta occurred during July, 1962, in Ecosystem II where the wheat supply rather than Blattisocius limited the Anagasta population. During the first half of the month 500 Anagasta adults emerged; most of these died before the middle of the month. The Blattisocius, which had been carricd by these adults, then concentrated themselves on the relatively few newly-emerged Anagasta adults. Ten of the latter, upon being vigorously shaken individually, yielded 500 Blattisocius. The average number of Blattisocius per adult Anagasta in Ecosystem II is less than one.

Regardless of its regulative capacity, the Blattisocius population generally 
varies in abundance with the adult $A n a$ gasta population. The abundance of prey (newly-deposited eggs) corresponds closely (in time) with the abundance of the adult parents, the longevity of such adults being less than 6 days. The phoretic Blattisocius population, namely, that portion carried about by the Anagasta adults, is representative of its population as a whole, although the number of Blattisocius per each vehicular adult usually varies inversely with the numbers of such adults.

An exceptional increase in phoresy in Ecosystems such as VII, X, and XII, wherein Blattisocius in cooperation with Exidechthis is prey-regulative, may be preliminary to an "outbreak." This occurs after the Anagasta population is reduced by egg predation to the point where the Blattisocius population either is relatively rare or is in the process of auto-annihilation. The presence of 20 or more Blattisocius upon each Anagasta adult sampled during a 2-week period may presage a decimation of the Anagasta population. Ordinarily in such an ecosystem, the average number of Blattisocius per adult Anagasta is one, and the maximum number less than ten.

The outbreak situation occurs after Blattisocius is temporarily eliminated by starvation and tne Anagasta popula- tion thus released from control. It is dependent upon Exidechthis being present but not by itself prey-regulative, and parasitization averaging from 30 to 80 per cent. Exidechthis can then occasionally replace enough of the prey so that the few completing their development do not deposit enough eggs to sustain the Blattisocius populations.

Exidechthis-induced outbreaks of $A n$ agasta occurred during 1959 in Ecosystem IV (fig. 10) and during 1962 in Ecosystem XII. In the former, the numbers of Anagasta adults jumped from 58 in June to 1,250 in July, and in the latter, from 121 in April to 1,173 in May. The July, 1959, outbreak was an effect of the release of Anagasta from control in May when for 16 consecutive days (May 11-26, inclusive) Anagasta adults were absent and there were no eggs to sustain Blattisocius. During this period, nine Exidechthis adults usurped nine Anagasta. The outbreak consisted largely of the progeny of 15 mated $A n a$ gasta that had emerged between May 27 and June 5. The 1962 outbreak in Ecosystem XII was preceded by an 11-day period (March 6-17, inclusive) in which Anagasta emergence was very limited and few eggs laid, 29 adults having been replaced by Exidechthis. The outbreak consisted largely of the progeny of $25 \pm$

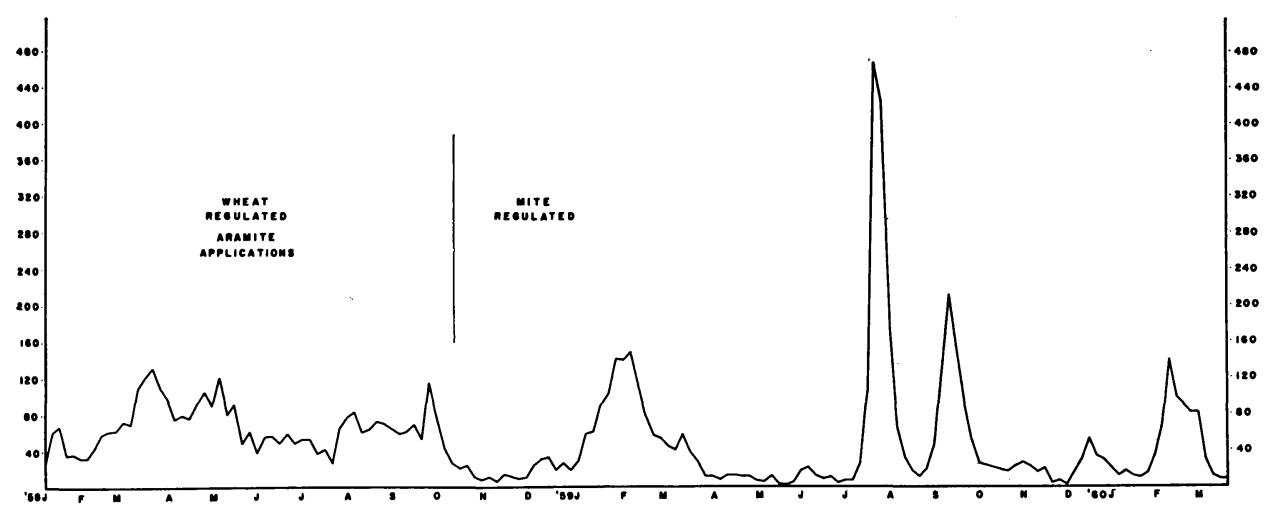

Fig. 10. Graph based on adult mortality ascertained daily depicting the population fluctuations in Ecosystem IV of 8,732 full-fed larvae of Anagasta regulated by the wheat supply from January, 1958, through October, 1958, and by Blattisocius in cooperation with Exidechthis from October, 1958, to March, 1960. The "outbreak" during July, 1959, resulted from the elimination of Blattisocius by starvation during a 16-day period in May. During this period no Anagasta emerged, 9 Exidechthis usurping the emergence of 9 Anagasta. 
moths that had emerged March 28 to 30 , inclusive. Blattisocius, aided by Exidechthis, subsequently resumed control, increasing from five per 10 moths (March 31) to 35 per two moths (April 7). "Nonregulative" parasitization, therefore, may greatly reduce and occasionally counteract the "regulative" predator-parasite cooperation.

When Exidechthis is present and by itself prey-regulative it destroys such a high proportion of the Anagasta population that the survivors do not produce eggs at densities sufficient for the sustenance of Blattisocius. The Exidechthis population thus eliminates the Blatti socius population. The individual Blat tisocius needs to find several eggs in order to complete its life cycle, whereas Exidechthis needs to find only one larva.

In ecosystems regulated by Blattisocius (Exidechthis being absent), the number of Anagasta attaining the adult stage each month ranges from 81 to 326 . In such ecosystems, in which all prey individuals are readily accessible to the predator, protection is spatial.

The regulating action of Blattisocius, in the absence of Exidechthis, was demonstrated in Ecosystem XIII during the year ending August 1, 1960, and in Ecosystems VIIIB and XIVB during a 12month period beginning in June, 1962.

The increments of wheat, Anagasta, and Blattisocius in Ecosystem XIII had been so arranged that a population equilibrium, with each organism having a constant age distribution, was attained by the end of July, 1959. Throughout the following 11 months, the moth population remained at a low, steady density although each allotment was being regularly replaced when 6 months of age, despite some of the wheat remaining unused (replacement on a 12-month schedule not having been instituted). A typical analysis of a replaced allotment when the rotation period is 6 months is as follows: Final weight $=68$ grains; weight of unused wheat $=36$ grains; number of adult moths $=38$.

The monthly average in numbers of adult moths produced per day (the survivors of mite predation) ranged from 3.4 to 9.0 , the maximum per day being 16. Moth population fluctuations of low amplitudes peaked at intervals ranging from 45 to 60 days (fig. 11). The regulatory action of the mite postponed for at least 8 months the complete destruction of grain in any allotment.

When the action of the mite appeared to be at a maximum, periodic 2-minute examinations of the surfaces of the ecosystem revealed an average of 43 roaming adult Blattisocius.

On April 28, 1960, the entire interior of Ecosystem XIII was sprayed with a 5 per cent solution of Aramite in acetone. Immediately before this treatment, the

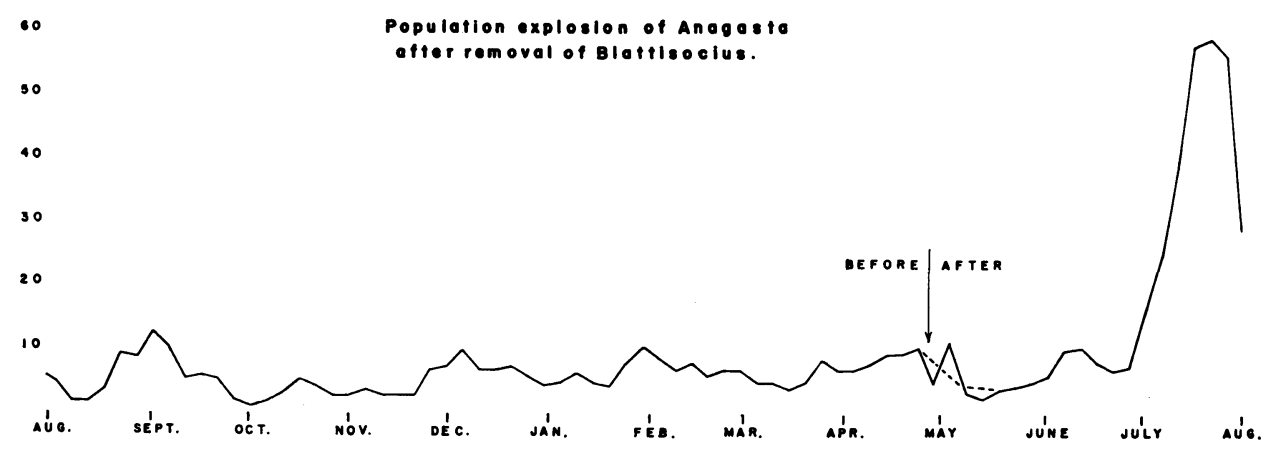

Fig. 11. Graph based on the mortality of Anagasta adults ascertained daily in Ecosystem XIII during the year ending August, 1960, depicting the population explosion resulting from the application to the ecosystem surfaces of a solution of 5 per cent Aramite in acetone and the consequent elimination of Blattisocius as a prey-regulating factor.

Dotted line of graph smooths out the fluctuation caused by the precocious adult mortality which resulted from excess residues of Aramite trapping some of the newly-emerged adults. 
entire moth population of 18 adults was removed from the ecosystem. The collection of phoretic mites was accomplished by vigorously shaking the vial containing these moths; 226 adult mites were obtained. The mite-freed moths were then returned to the ecosystem.

The larval consumption of the accumulated food supply, owing to the elimination of the predatory mite population, resulted in an explosion of the larval-prey population (fig. 8). The explosion was represented by the large numbers of Anagasta adults emerging throughout June and July. The moth eggs deposited for $101 / 2$ months prior to the elimination of Blattisocius yielded 1,967 Anagasta adults, whereas the moth eggs deposited during the following $21 / 2$ months with Blattisocius absent yielded 2,074 Anagasta adults, an immediate increase in the average number of adults emerging per day from 6 to 27 . During a 13-day period in the middle of July, the daily production of adults averaged 60 ; the daily maximum was 66 . The explosion ended on August 24. Shortly thereafter, the ecosystem was inoculated with Exidechthis.

Throughout the 24 wheat allotments of an ecosystem, the distribution at a given time of the developing larval population of Anagasta under predatory regulation may be uniform, whereas under food shortage limitation this population is concentrated in from six to eight allotments - an effect of the higher rate of wheat consumption.

When Exidechthis and Blattisocius are in competition for Anagasta as a source of food in ecosystems without refuges, Exidechthis first eliminates Blattisocius, then its host and consequently itself.

\section{EXIDECHTHIS AS A DENSITY-GOVERNING FACTOR}

Exidechthis in the laboratory ecosystems is an efficient regulator of $A n a$ gasta populations, although in nature it may never be regulative but merely contributory (Woodworth, 1908). In the laboratory it becomes nonregulative when about 10 per cent or more of the larval Anagasta population escape annually, and annihilative when 2 per cent or less escape annually. These percentages, based on the proportions of the potential Anagasta adult population replaced by the adult Exidechthis show the narrow range in which Exidechthis is regulative. As in nature, the range of ecological efficiency is relatively narrow (Slobodkin, 1962).

In the Anagasta systems, Exidechthis parasitization becomes annihilative when the depth of the wheat allotment is less than $4.5 \mathrm{~mm}$, i.e., when the area traversed by the average Exidechthis female equals the area of discovery of the species.

The Anagasta population in Ecosystem IV, for example, had been under regulation by Blattisocius, aided by $\boldsymbol{E} x$ idechthis, for a year prior to its present apparent regulation by Exidechthis. This change in the regulating mechanisms was accomplished by changing the diameter and depth of the allotment habitats from $31 \times 28 \mathrm{~mm}$ to $90 \times 3 \mathrm{~mm}$, effective May, 1960 (table 6). Because parasitization by Exidechthis was thus rendered annihilative, arbitrary maintenance of the Anagasta population by the occasional introduction of a gravid female was necessary prior to November, 1962 , when a $49 \mathrm{~mm}$ cardboard disc was placed on each allotment.

Parasitization at present closely approaches the regulative threshold exhibited in Ecosystem I. Since the populations of Anagasta in Ecosystems VIA and VIB were subject to annihilation by Exidechthis, they also received an occasional addition of mated Anagasta females (table 6 ).

It is noteworthy that Wheeler (1911) presumed the joint annihilation of a host and its parasite to have occurred repeatedly in geological time. He stated that for survival a specific parasite must not overstep its host's "margin of vital- 
TABLE 6

24-MONTH PRODUCTION OF ANAGASTA AND EXIDECHTHIS ADULTS IN ECOSYSTEMS I, IV AND VIB IN WHICH THE POPULATIONS ARE AT OR NEAR THE THRESHOLD OF SECURITY

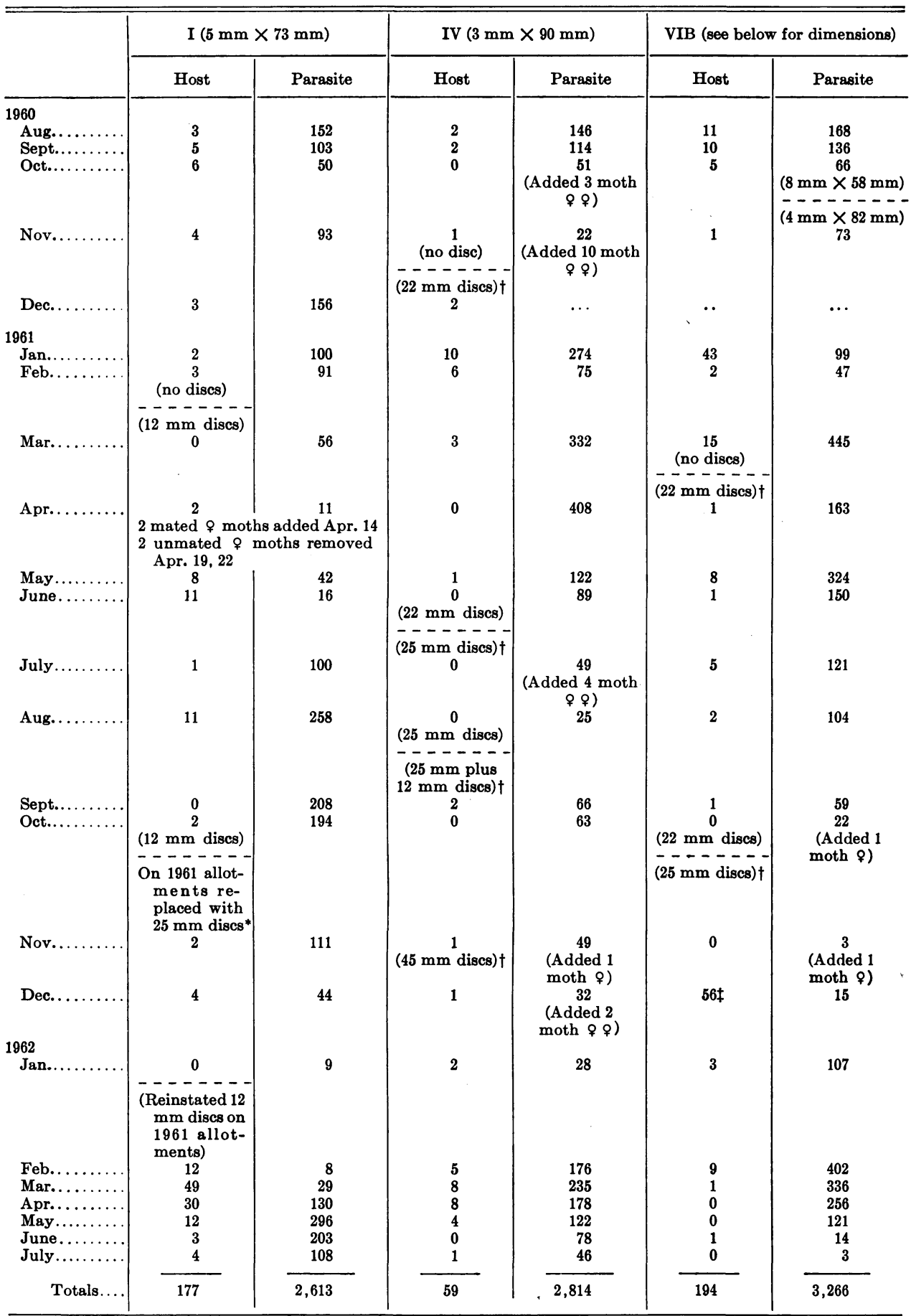
* Added protection reduced Exidechthis emergence from 9 every 3 days to 1 every 3 days during a 4 -month period.
+ Attempts to establish a threshold of security by the addition of a transparent disc or by an increase in disc size. $\$ 47$ moths removed upon emergence. 
ity"; i.e., the portion of the host population that can be sacrificed to the "accidents" of the environment.

The preclusion of regulative Blattisocius predation by regulative or nearregulative Exidechthis parasitization occurred in Ecosystems IV, VIA, VIB, and XI, as well as in Ecosystem I.

In Exidechthis-regulated Anagasta ecosystems, the equilibrium position (steady density) is a function of intraspecific competition by Exidechthis for its food, the larvae of Anagasta, this balance being permitted by the minimum protection afforded Anagasta by structural refuges. When host-regulative, Exidechthis eliminates all other extrinsic sources of Anagasta mortality.

The data derived from Ecosystem I in which Exidechthis has been host-regulative for about three years show that the annual parasite-host ratios of adult females, Exidechthis/Anagasta, varied from 55:1 in 1961 to $16: 1$ in 1962. For a 24-month period, August 1960 to July 1962 , the adult female ratio was $30: 1$ (table 6). At this ratio the per cent parasitization was 94 and the number of Anagasta larvae becoming full-fed per month averaged 116.

In ecosystems in which the Anagasta populations are wheat-regulated, the annual female ratios varied from 9:1 as in Ecosystem III to 0.14:1 as in Ecosystem IX. In the former, the per cent parasitization was 82 and the number of Anagasta larvae becoming full-fed per month averaged 383; in the latter, the per cent parasitization was 7 and the number of Anagasta larvae becoming full-fed per month averaged 251. (The population of 383 larvae became full-fed on a quantity of wheat equal to that completely utilized by a population of 251 full-fed larvae.)

It appears, therefore, that in order for Exidechthis to be host-regulative the adult female ratios must average at least $10: 1$, the pivotal ratio. Only with such ratios will the Exidechthis population be sufficient to parasitize all but two of the progeny of one reproductive Anagasta female. When the pivotal ratio is exceeded the fluctuations in Anagasta abundance are Exidechthis-determined. Lacking such an increase the fluctuations in Anagasta abundance are Anagasta-determined. Apparently, when a prey population is maintained at minimum survival density by a predator population, the numbers of adult predators greatly exceed the numbers of adult prey.

In Exidechthis-regulated ecosystems, fluctuations (displacements from the steady density) exhibit minimum ampli-

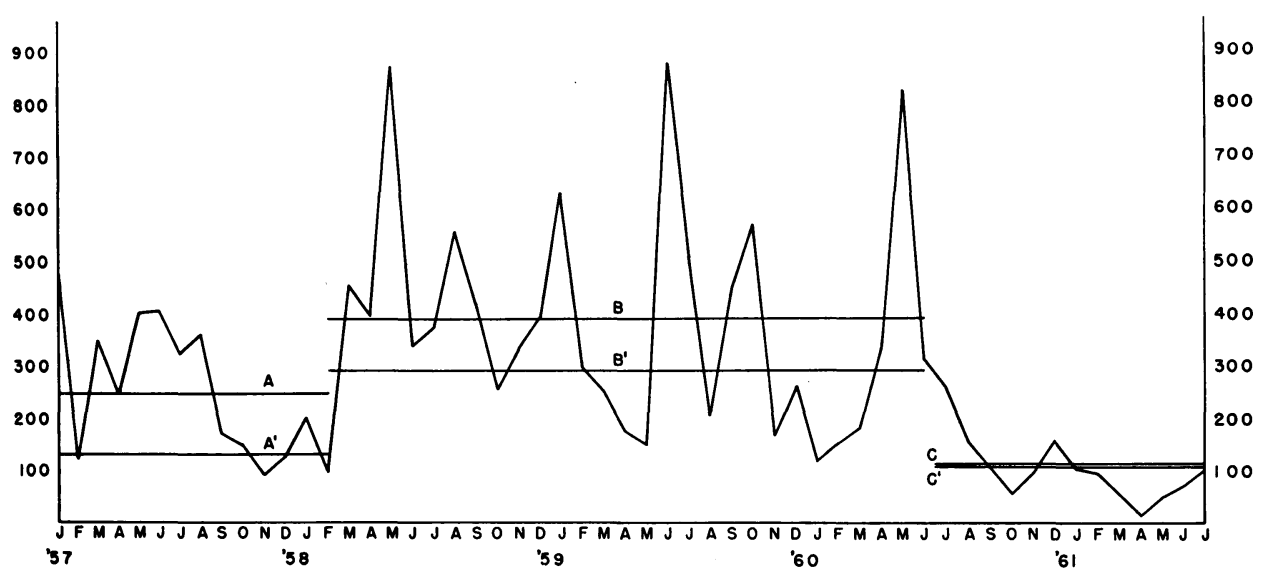

Fig. 12. Graph based on adult mortality of Anagasta and Exidechthis ascertained daily in Ecosystem I depicting the population fluctuations of the full-fed larvae of the self-perpetuating Anagasta population during 55 consecutive months. The average abundance of this Anagasta population as determined by predatism in conjunction with parasitism, the wheat supply and parasitism alone are indicated by lines $\mathrm{A}, \mathrm{B}$, and $\mathrm{C}$. The related parasitization is indicated by lines $\mathrm{A}^{\prime}, \mathrm{B}^{\prime}$, and $\mathrm{C}^{\prime}$. 


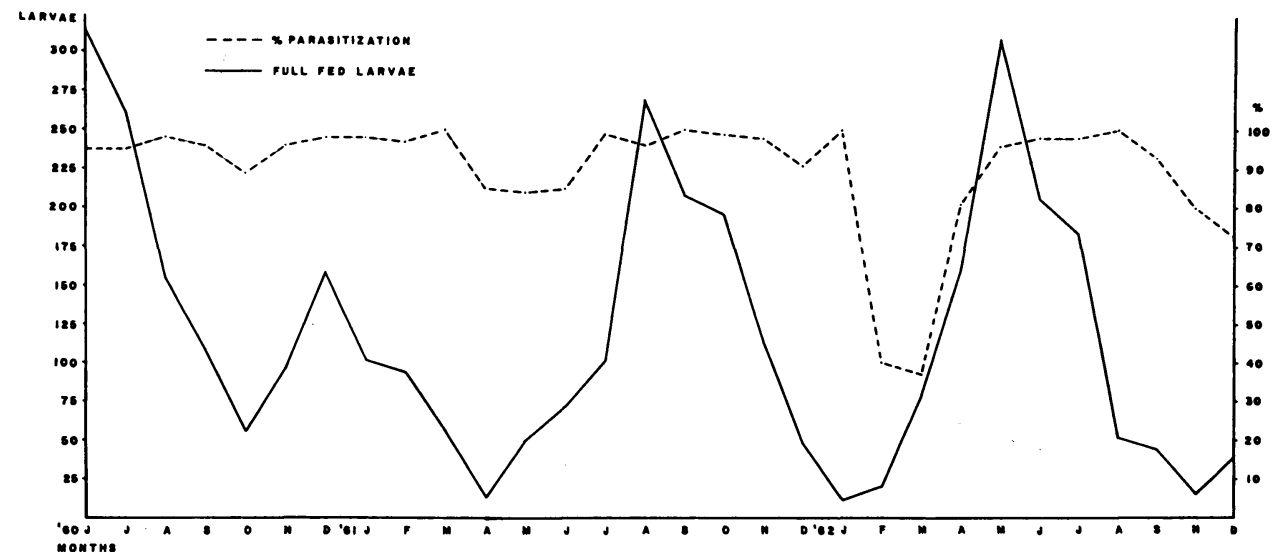

Fig. 13. Graphs based on adult mortality ascertained daily depicting the fluctuations of a fullfed Anagasta larvae population and of the regulative per cent parasitization in Ecosystem I from June, 1960 to December, 1962. Note that the average fluctuation amplitude is about one-third that which occurs when the Anagasta population is wheat-regulated and that the fluctuation interval (periodicity) is about twice as long (compare with graph in fig. 12).

The marked drop shown in the per cent parasitization resulted from the increased protection from Exidechthis attack afforded by the temporary replacement of the $12 \mathrm{~mm}$ discs by $25 \mathrm{~mm}$ discs, a replacement limited to a 3-month period ending January 15, 1962.

tudes (figs. 12 and 13). This is possibly an effect, as postulated by A. J. Nicholson (personal communication), of a few larvae (those in cocoons) spending a relatively long time exposed to the parasite population, whereas the majority of the larvae, being free moving, are exposed for very short periods.

As Smith (1939) points out, when a parasite possessing high powers of discovery interacts with a host having a low power of dispersal, the interaction tends to produce slight fluctuations at a low average density. An additional effect of such an interaction, as demonstrated in Ecosystem I, is that natural enemy regulation of a population de- creases fluctuation frequencies (fig. 12).

As observed by Takahashi (1959), it is apparent that the prey-finding efficiency of an Exidechthis population varies with any change in the depth of the prey-inhabited food supply and in the correlated surface area search. As Takahashi also noted, the growth rate of the parasite population varies with such changes, slowing up as the depth increases.

Exidechthis, however, is completely nonregulative either when the wheat habitat exceeds $10 \mathrm{~mm}$ or when, regardless of its depth, the habitat is enlarged by the addition of vermiculite.

\section{HISTORY OF ECOSYSTEM I}

During the past 7 years the oldest ecosystem (I) has exhibited in sequence three phases of population limitation: regulation of Anagasta by Blattisocius in cooperation with Exidechthis, limitatation of Anagasta by the wheat supply, and regulation of Anagasta by Exidechthis alone. Inasmuch as this ecosystem has been in continuous equilibrium for over 70 months, regulated by forces which have been demonstrated repeat- edly in the other ecosystems, a review of its operation seems desirable.

Exidechthis has been present continually from the initiation of the ecosystem (fig. 12). Its parasitic action, whether or not host-regulative, apparently reduces the intensity of the intraspecific competition of the newly-hatched Anagasta larvae for the wheat. When regulative it completely replaces such competition.

The monthly average of Anagasta 
adults produced for each distinctive density-governing period (not including the adult Anagasta populations for the two transition months) is:

117 adults per month for the period of Blattisocius-Exidechthis regulation

$831 / 2$ adults per month for the period of internecine mortality of Anagasta

7 adults per month for the period of Exidechthis regulation prior to August, 1963.

The searching capacity of the parasite population was increased and made regulative by decreasing the depth of the wheat allotments (the habitat of the Anagasta larvae) from 14 to $4.5 \mathrm{~mm}$. This change in habitat dimensions decreased the "structural" protection afforded the host larvae. (Since every allotment of wheat consists of 120 grains, the decrease in depth increased the diameters of the exposed surfaces from 44 to $73 \mathrm{~mm}$ ).

The Anagasta population in the ecosystem prior to April 1, 1958, was under regulation by Blattisocius in cooperation with Exidechthis. During the subsequent 27 months, as a consequence of rendering Blattisocius ineffective by Aramite applications (fig. 14), the $A n a$ gasta population was regulated by the supply of wheat, internecine larval strife eliminating the surplus larvae prior to feeding.

During this time, parasitization by Exidechthis averaged 82 per cent, with the Exidechthis population attaining a maximum in density and abundance, 728 in May, 1958 and 678 in June, 1959. This population, although density-dependent (its abundance being governed by the abundance of the larval prey),

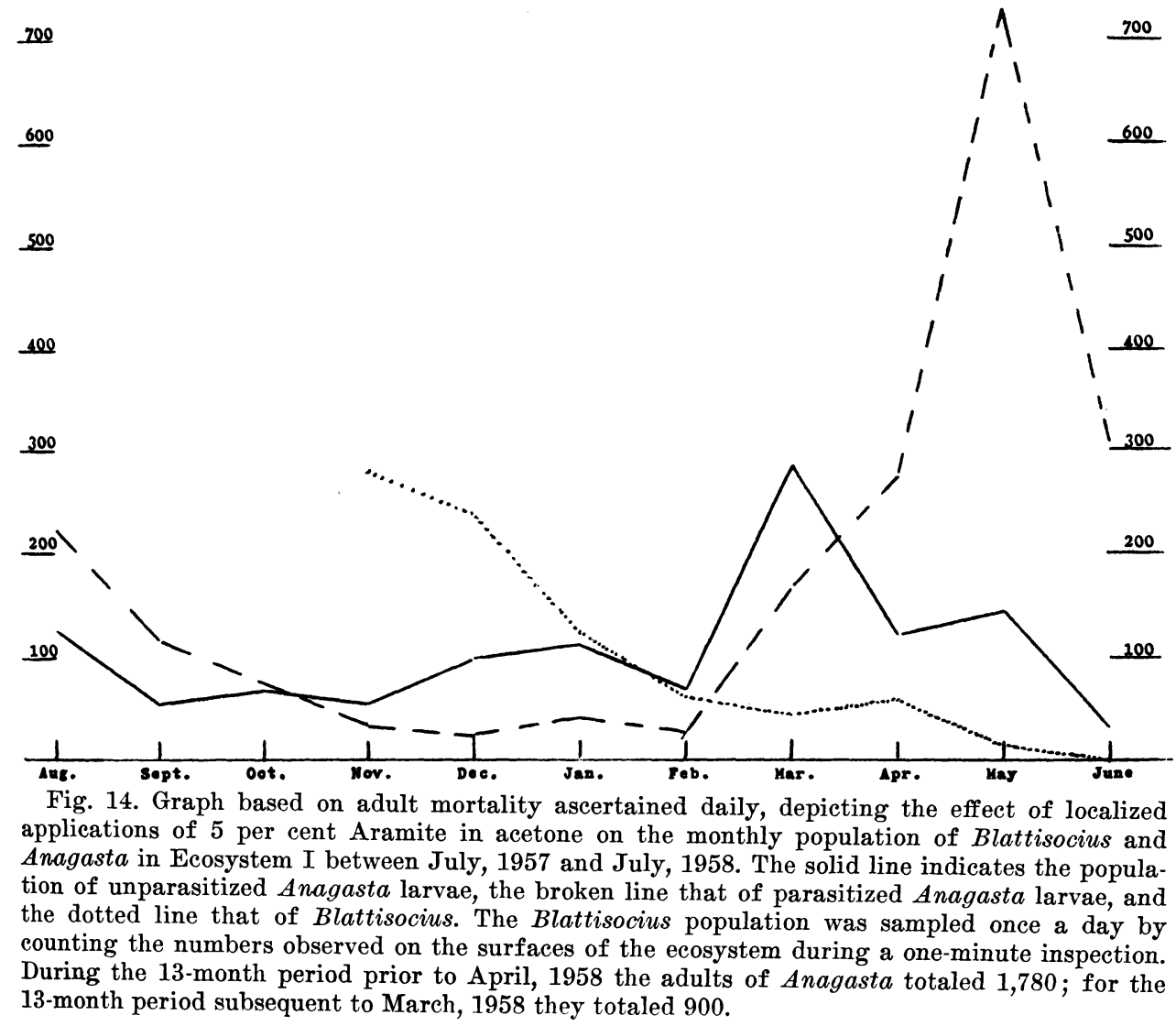


had no "control" over the host population, the abundance of the latter being "controlled" by the supply of wheat (Flanders and Badgley, 1960).

Under such circumstances, the fluctuations of a population may attain amplitudes and frequencies exceeding those occurring in the absence of natural enemies. This situation is presumably an effect (1) of the numerical increase in the full-fed larval population that occurs when the early larval instars are parasitized and (2) of the decreased internecine action of the newly-hatched larvae effected by the replacement of adult Anagasta by adult Exidechthis.

The final conversion of larval habitat dimensions, begun on January 15, 1960, was completed by July 1, 1960. (The entire ecosystem wheat supply, consisting at all times of 24 allotments in all degrees of depletion, was replaced during this period.) As a result of this change in habitat allotments, the Exidechthis population destroyed over 92 per cent of the larval host population during 1961 and 1962.

For the first 14 months the egg-feeding mite Blattisocius, in cooperation with the larval parasite Exidechthis, held down the Anagasta population to a total of 3,518 full-fed larvae (parasitization 52.3 per cent). For the next 27 months the Anagasta population, released from natural enemy control beginning January, 1958, by Aramite applications (fig. 14), consisted of 10,516 larvae (parasitization 74.8 per cent) that became full-fed by consuming the wheat supply rapidly. For the last 14 months following a decrease in depth of allotment habitats from $14 \mathrm{~mm}$ to 5 mm Exidechthis held down the Anagasta population to a total of 1,636 fullfed larvae (parasitization 95.3 per cent) (fig. 12).

From July, 1960 to June, 1963 inclusive, the Anagasta population was regulated at extremely low densities by 3,335 Exidechthis. Such densities preclude internecine larval strife.

During this regulative period of 3 years, both the Anagasta and the Exidechthis populations were sustained by a total production of 243 adult moths. Some of these had no progeny, the opposite sex being absent at the time. Consequently, the larval progeny derived from about three gravid females per month supported a parasite population averaging 93 per month, the approximate number needed to parasitize all but about two of each female's complement of larval progeny.

Since the mating of all adult Anagasta females might be insured by doubling the number of allotment habitats and as a consequence the percentage of regulative parasitization increased to 98 per cent, a double ecosystem (XV) was set up in 1963, formed by joining two duplicates of Ecosystem I. The ecosystem would probably become defunct should 4 months elapse without an Anagasta male becoming adult concurrently with an Anagasta female.

As soon as Exidechthis became preyregulative, the subsistence of Anagasta was restricted to such a small portion of the wheat supply that the allotments were replaced once a month instead of once a week, the residue of each allotment being removed after a 2-year exposure rather than after a 6-month exposure. Analyses of the removed allotments showed that from 9 to 21 grains of wheat remained intact and that in most allotments 100 per cent of the larvae had been parasitized. The allotments not so parasitized yielded from 1 to 10 adult Anagasta. Apparently the host-frequented areas were not uniformly traversed by the parasite.

Since March 1, 1961, the perpetuation of the parasite control of the Anagasta population has been enhanced by the placement of a $12 \mathrm{~mm}$ glass disc on the surface of each wheat allotment adjacent to the wall of the habitat. Presumably the disc so placed, by constituting a structural refuge for the Anagasta larvae, increases the chances of (1) a few larvae escaping parasitization; and 
(2) the coincident emergence of adult males and females, an essential factor in reproduction of the prey.

The effect of increasing the protection of Anagasta from Exidechthis only slightly by temporarily substituting 25 $\mathrm{mm}$ refuge dises for the $12 \mathrm{~mm}$ refuge dises was also demonstrated in this ecosystem (fig. 13).

This disc substitution was made on the ten youngest habitat allotments for a 3-month period beginning in the middle of October, 1961, the $12 \mathrm{~mm}$ discs replacing the $25 \mathrm{~mm}$ dises in the middle of January. The larval Anagasta during this 3 -month period was subject to attack by 263 Exidechthis females.

The first observed effect was an "outbreak" of 12 moths (nine females and three males) during a 2-week period beginning February 1. This moth emergence was unique in that it was not accompanied by a simultaneous increase in parasite emergence. The larval progeny of these moths were subject to attack by only 17 Exidechthis, the total number emerging during January and February, 1962.

The result of this combination of circumstances was a second outbreak of 77 moths during the month ending April 16, a moth increase, however, accompanied by the usual simultaneous in- crease in parasite emergence. The total moth emergence for the 12 months prior to this second outbreak was only 56 (table 6).

In Ecosystem I each wheat allotment now yields an average of 60 parasites. This parasitization conserves one-tenth to one-fourth of the wheat. The 60 parasites represent 60 full-fed parasitized Anagasta larvae which become full-fed with one-third less wheat than required for 60 unparasitized full-fed larvae.

This ecosystem demonstrated the maximum conservation of wheat for the maximum period of time. However, Blattisocius may be almost as effective when, as in Ecosystem VIIIB, the depth of wheat is $3 \mathrm{~mm}$. The regulative action of Blattisocius, unlike that of Exidechthis, is quite variable in efficiency when measured by the conservation of wheat. As stated by Smith (1935), the effectiveness of a natural enemy is measured by the host density at which it is able to destroy the surplus progeny, that is, progeny which unless destroyed would result in an increase in the host population and a decrease in surplus food. The potential prey-regulative value of $\boldsymbol{E} x$ idechthis may be less than that of Blattisocius, the allotment-habitat dimensions handicapping Exidechthis to a greater extent.

\section{DISCUSSION}

In the Anagasta ecosystems the maximum Anagasta population possible is constant because a constant amount of food is periodically supplied. As in nature, the limiting effects on a population of living space and of the quantity of available food are precluded by the regulatory action of a natural enemy. Likewise, one species of regulative natural enemy will be replaced by one of greater effectiveness. Such actions result in the food supply being an unlimited resource always in excess of the needs of the population, provided, of course that, as in nature, the food supply is periodically renewed. The sequence of prey genera- tions is continuous and overlapping, enabling the predator to destroy all but the replacement number of prey, irrespective of the population level. As Muir (1913) noted under field conditions, the prevailing prey-predator ratio is determined by the capacity of the predator to discover the prey.

The Anagasta ecosystems demonstrate that regulatory prey-predator interaction is possible because of two circumstances: (1) overlapping of prey generations, insured by the chronological sequence of renewed allotments of food, which permits continuity in predator reproduction; and (2) an average 
threshold of prey protection which insures that deaths equal births annually, with the replacement of parents by an equal number of progeny.

The allotment-habitat of the Anagasta ecosystem is the ecological equivalent of the "heterogeneous microcosm" of Gause (1934), the "sphere of parasitic action" of Flanders (1935) and the "universe" of Utida (1950). That such biocoenotic habitats are localized and discontinuous episodes constituting the life of an ecosystem was recognized by Gause in his citation of Cockerell's observation on a persistent scale insectshrub ecosystem in New Mexico, an ecosystem (in which prey refuge probably is spatial) presumably consisting of localized short-lived prey-prédator populations (episodes) characterized by generations more or less discrete.

Regulatory prey-predator populations in the Anagasta ecosystem occasionally exhibit a peculiar type of fluctuation which may be designated the "long interval" fluctuation (fig. 10). This type of fluctuation is caused by the auto-mortality of the predator through starvation (superparasitism) as a result of excessive prey destruction and may exhibit gradations which culminate in "outbreaks" as noted in the AnagastaBlattisocius-Exidechthis Ecosystems IV and XII.

When, as a result of over-exploitation of the prey, a long period of overlapping prey generations under regulation by natural enemies is followed by a short period of more or less discrete (separate) generations, the prey population is temporarily released from regulation and explodes.

An outbreak, therefore, is the result of an excessive predatory reduction of prey density which annihilates the predator population. The prey population, thereby temporarily released from the controlling agents, overpopulates the ecosystem. This can happen only when compensatory factors are lacking as in the Anagasta ecosystems. A high percentage of mortality by one factor can be either important or unimportant according to whether it replaces or does not replace some other cause of mortality (Compere and Smith, 1932). Host mortality by Exidechthis may be critical when, as in Ecosystems IV or XII, it results in greatly reduced Balttisociuscaused mortality.

In nature, as Van der Vecht (1951) pointed out, an outbreak of a prey population is likely when it is under regulation by a predator whose adult life is relatively short and which attacks only one stage or several stages of the prey. With such an interaction, fluctuations in the susceptible stages of the prey's population may be so accentuated in the course of time that the dependent predator population approaches annihilation, permitting the prey to over-populate its environment. In the Anagasta-Blattisocius-Exidechthis ecosystem, such an explosion utilizes the abundant unused plant material which had accumulated during the long period of regulatory prey-predator interaction.

In California citrus orchards, outbreaks of the scale, Saissetia oleae, may result from the auto-mortality of Metaphycus helvolus when the latter efficiently destroy the scale population (Flanders, 1949). However, as pointed out by Solomon (1949), when a predator keeps the prey population density at a moderately low level, other influences such as food or space shortages or disease may not come into operation.

The "recovery" fluctuations following an outbreak initiated by a predator-induced one-stage even-brooded condition may temporarily exhibit a "lag" between the prey fluctuation and the correlated predator fluctuation.

The introduction of Exidechthis into Ecosystem XIII, 21/2 months after the Aramite-induced Anagasta outbreak in July, 1960, resulted in a distinct lag between prey and parasite fluctuations, prey abundance attaining its peak in December, that of the parasite in February. The sequence of monthly preyparasite ratios was 165:0, 151:0, 262:32, 
$371: 136,6: 218,1: 307,3.130$, and $0: 32$. In this sequence, an Anagasta adult emergence averaging eight females per day during a 30 -day period ending December 18, 1960, was followed by an Exidechthis adult emergence averaging nine females per day during a 40-day period ending February 28, 1961.

This annihilation of Anagasta resulted from the lack of protection, the parasites ultimately representing the entire larval progeny of the Anagasta population. A 100 per cent parasitization was possible because of the "eating down" of the protective layers of wheat by the Anagasta larvae.

Perpetuation of this ecosystem was accomplished by introducing gravid Anagasta females, two on April 14, and four on May 12. Meantime, to prevent the repetition of Anagasta annihilation, protective $12 \mathrm{~mm}$ glass dises were placed in position on the surface of each habitat allotment.

A similar lag between prey-parasite fluctuations occurred during the first half of 1962 in Ecosystem VIA after a single Exidechthis had been introduced into an Anagasta-Blattisocius population occupying $90 \mathrm{~mm} \times 21 / 2 \mathrm{~mm}$ habitat allotments.

The ensuing monthly prey-parasite ratios were 122:0, 490:5, 222:156, $44: 412$, and $2: 92$, the peak of prey abundance occurring in February, that of the parasite in April. The "lag" subsequently disappeared because of the overlapping of prey generations. Since the allotment habitats had provided Anagasta no protection whatever from the Exidechthis, $25 \mathrm{~mm}$ disc protection was added in order to enable the parasite to be regulative. This proved inadequate, so in November, 1962 , the $25 \mathrm{~mm}$ disc was replaced by a $49 \mathrm{~mm}$ disc. (The effect of this change remains to be determined. However, the 1963 census data in Ecosystems IV, VIA, and VIB are indicative of regulative parasitization.)

Laboratory experiments demonstrating prey-predator interaction in "uni- verses" in which generations are more or less sharply separated necessarily exhibit the "lag" phenomenon. Burnett (1958) pointed out that such "universes" are useful only in demonstrating how a simple nonregulatory prey-predator interaction may be modified when one or more additional variables are added one at a time.

With Anagasta and Exidechthis, for example, parasitization at different developmental stages of host has a differential effect upon adult emergence of host and parasite. This difference is revealed only by life-cycle correlations between a discrete host generation and a dependent discrete parasite generation (fig. 15). Earlier, the senior author (Flanders, 1935) demonstrated with discrete generations of prey-predator populations (Sitotroga and Trichogramma) that the maximum per cent mortality is first attained when the density of available prey approaches the predator population's total reproductive capacity.

It is apparent that in many previously described prey-predator experiments, demonstrations of regulatory population interactions were precluded not only by the lack of proper prey protection, but by the sharply separated generations.

In Anagasta ecosystems in which the Anagasta population is governed by the supply of wheat and in which nonregulative prey-predator interactions occur, the population fluctuations are of the "short interval" or nongradation type. The predator fluctuation under such conditions is merely a reflection of the prey fluctuation; both occur synchronously (Fisher, 1962).

In such a situation with a constant food supply, the periodicity of Anagasta increase and decrease appears to be the effect of variations in the intensity of the intraspecific competition for requisites, that of the newly-hatched larvae for space, that of the feeding larvae for the wheat, and that of the predator for its prey (the Blattisocius 


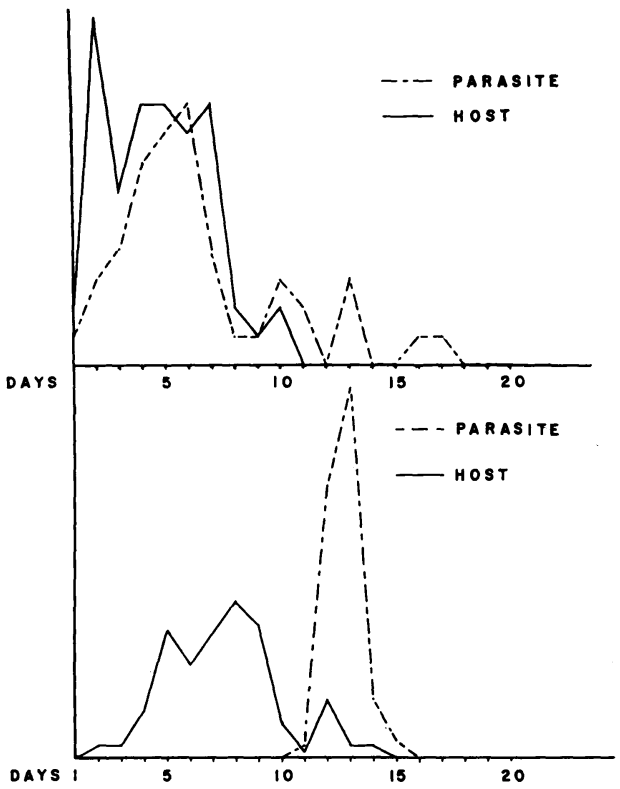

Fig. 15. Graphs based on adult emergence ascertained daily depicting the synchronization of adult emergence when a single generation of Anagasta is parasitized by a single generation of Exidechthis (temperature $27^{\circ} \pm 3$; relative humidity 55 per cent \pm 5 ).

Upper graph based on 112 Anagasta larvae 48 per cent parasitized when one-quarter grown. Emergence of adult Anagasta and adult Exidechthis tend to coincide if the Anagasta larvae are one-quarter grown when parasitized. This is an effect of the retardation of parasite development during the growth of the host larvae.

Lower graph based on 271 full-grown Anagasta larvae, 46.5 per cent parasitized.

Emergence of Anagasta precedes that of Exidechthis by about 6 days if the Anagasta larvae are full-grown when parasitized. This is an effect of the minimum life cycle of Exidechthis exceeding the pupal period of Anagasta by about 6 days.

for Anagasta eggs, the Exidechthis for Anagasta larvae). Apparently even when the food supply is adequate, fluctuations in population densities are inevitable (Nicholson, 1950).

The predilection of the Anagasta female to deposit her eggs on the silken strands spun between the particles of wheat and the particles of vermiculite tends to reduce contact between newlyhatched larvae. The variability in such larval contacts is indicated by the differences in time in the "binding together" of the habitat particles by the silken strands. This binding varies for individual allotments from one to two months after their placement in the ecosystem. Variability in numbers (fluctuation) in the Anagasta ecosystems as presently constituted is much greater than would be the case if they were more complex (Solomon, 1949).
Every self-perpetuating persistent population is of necessity a deviationcounteracting system. In such a system in the long run, as pointed out by Woodworth (1908), mortality equals the natality of new individuals. In the laboratory, as in the field, the number of living individuals fluctuates about a numerical mean (steady density), the fluctuations being toward population extinction. Balance in any population is primarily the function of food consumption, the population being regulated either by its utilization of food or by its serving as food. Regulation by the latter necessarily precludes the regulative action of the former.

A predator of a phytophagous animal attains balance through its densitydependent relation to prey abundance, the predator abundance generally varying with that of its prey. But, in the 
field, relatively few of the manifold prey-predator interactions are prey regulative, although balance so attained is basic to the economy of plant life. This is indicated by the facts that in nature the kinds of predators greatly outnumber the kinds of prey and that two types of population balance, "reciprocal" and "nonreciprocal" occur. These types of balance are represented in the $A n a$ gasta ecosystem.

In the "reciprocal" type, the action of the controlling factor must become more severe when the population density increases and less severe when the density decreases (Nicholson, 1937); that is, the action of the controlling factor effects a variable density-dependent mortality (Smith, 1935). Thus, in any mature population, chance of survival and rate of population increase vary inversely with population density. As stated by Nicholson (1954b), a sustained state of corrective reaction to disturbing forces which insures the persistence of a population system is a reciprocal balance. In such a balance the densities of prey and predator oscillate both in space and in time, but the general level of the prey is held below that permitted by available nutriment.

In any prey-predator interaction, the mortality of the prey effected by the predator is reflected in the predator's increase and decrease. This mortality, however, as pointed out by Woodworth (1908), is either "contributory" (nonreactive) or "effective" (reactive). Contributory mortality merely retards the rate of increase and is nonreciprocal, that is, the prey-predator interaction affects the steady density of the predator but not that of the prey. Effective mortality is reciprocal, that is, the mortality of one of two interacting organisms determines the steady density of the other. Accordingly, the balance at- tained by an organism is either nonreciprocal or reciprocal.

A predator population in "reciprocal" balance destroys a higher percentage of prey individuals when the latter are numerous than when they are scarce, but when the predator is in nonreciprocal balance, the contrary may be the case. However, in the Anagasta ecosystems the prey-predator ratios are more or less constant when the predator balance is nonreciprocal. When such a balance is exhibited by a predator, its abundance decreasing and increasing synchronously with the prey population, it has a density-dependent relation which is not prey-regulative.

When an Anagasta ecosystem consists of two food chains, one of wheat, Anagasta and Blattisocius, the other of wheat, Anagasta and Exidechthis, with none of the natural enemies prey-regulative, each population is in equilibrium (balance), the abundance of the natural enemy being dependent on the abundance of Anagasta, but not reciprocally. This occurs when the amount of wheat is arbitrarily constant and a cover of vermiculite prevents the regulation of $A n$ agasta by either Blattisocius or Exidechthis. It is apparent that when a predator population is not prey-regulative, its density is limited at a level indirectly determined by the food depletion action of the prey.

When a natural enemy of Anagasta is prey-regulative, its balance is reciprocal. When Blattisocius and Exidechthis are cooperatively prey-regulative, as in Ecosystems X and $\mathrm{XII}^{3}$, each population (of Blattisocius, and of Exidechthis) is in a state of reciprocal balance (equilibrium) although the abundance of one may vary inversely with the abundance of the other.

To recapitulate balance differentiation: In an ecosystem in which balance

\footnotetext{
${ }^{3}$ The Exidechthis populations in Ecosystems X and XII were eliminated early in 1963 by trapping the newly emerged adults within their allotment-habitats. This was accomplished within a 12-week period by superimposing covers of transparent glass on all the allotments likely to contain parasitized hosts and destroying the newly emerged Exidechthis. The adults of Anagasta that emerged in the closed allotment-habitats were released.
} 
in the Anagasta population is attained either by competition for space or by competition for the wheat supply and both the Blattisocius and the Exidechthis populations are competing for Anagasta each natural enemy is in balance, not because of a reciprocal selfgoverning action but because of its selfadjustment to an otherwise controlled Anagasta population, a dependency which results in their abundance varying directly with that of Anagasta.

In the Anagasta ecosystems, therefore, both the Exidechthis and Blattisocius populations may represent two types of balance, one involving prey regulation, the other not. When preyregulative, the prey-predator mortality is effective (reciprocal) ; when non-preyregulative, the mortality is contributory (nonreciprocal), prey abundance (available food) determining the predator's equilibrium position, but without predator abundance having any effect on the equilibrium position of the prey. As pointed out by A. J. Nicholson (personal correspondence), "In one situation, governing reaction [being reciprocal] influences both the production and the depletion of a requisite; in the other [being nonreciprocal] it influences depletion only."

In nature, the abundance of a general predator may determine the nonreciprocal balance of a particular prey as in the case of the food chain noted earlier of plant roots, the coccid Chavezia caldasiae, the ant Rhizomyrna fuhrmanni and a complex of predatory ants. The populations of the nigra scale in California are in nonreciprocal balance at very low densities, this being effected by populations of Metaphycus helvolus produced on other host species.

The Anagasta ecosystem differs essentially from an ecosystem in nature only in the immediate availability of food and habitat to its organisms, the lack of emigration and immigration, and in the constancy of physical conditions. In both artificial and natural ecosystems the density of a population is the combined effect of its own specific character and ability, the general suitability of the environment (physical conditions and quality of food as they affect rate of reproduction and survival), the amount of space and of food, and the prevalence and efficiency of enemies, competition and disease (Solomon, 1949).

Whenever a predator population is in reciprocal balance, a portion of a given amount of plant food is unused during the intervals of replacement despite the fact that the used amount supported several generations of the phytophagous prey.

It is apparent that in uniform environments and with population generations overlapping, population fluctuations are inherent, those of prey and of predator tending to coincide.

Obviously, all conclusions drawn from simplified experiments must be referred back to natural situations to determine their general validity.

\section{PHENOMENA CORRELATED WITH PREY-PREDATOR INTERACTIONS}

Prey-predator interactions may determine in large part the incidence of disease epizootics. In three Anagasta ecosystems, epizootics of a spore-forming crystalliferous bacterium have occurred spontaneously; in 1961 in Ecosystem XIVA, and in 1962 in Ecosystems II and XII. In each instance, the infection of Anagasta larvae followed closely the temporary elimination of the Blattisocius population by starvation, a starvation effected by a host-egg-free period that exceeds in length the life of the adult Blattisocius (10 days at $27^{\circ} \mathrm{C}$ ). Such starvation may occur in wheat-regulated as well as in Blattisocius-regulated ecosystems. It precedes the erowding of the habitat allotments 
with Anagasta larvae, crowding that is conducive to bacterial infections.

Ecosystem XIVA was initiated on October 2, 1960, in the usual manner but without Exidechthis. Any Blattisocius that may have been present were incidentally eliminated by starvation during a 20-day host-egg-free period ending January 15, 1961. Overcrowding was first evident during the week ending January 20, 1961, when 39 second-generation larvae were forced out of the accrued 15 habitat allotments. It was again evident during the week ending February 28 when 16 such larvae were forced out of the accrued 21 habitat allotments. Prior to this time very few of the free-roaming larvae showed evidence of bacterial disease. However, shortly thereafter, during the week ending March 9, 29 larvae forced out of the habitat allotments by overcrowding succumbed to bacterial disease, each becoming characteristically black.

Periodic examinations of adult moths failed to show any Blattisocius; consequently, during the last week in March $100+$ Blattisocius were introduced. The purpose of this introduction was to determine whether Blattisocius activity may have been in part responsible for the very low incidence of bacterial disease in the Anagasta ecosystems during the preceding four years.

In Ecosystem XIVA from late February to late December, 1961, every habitat allotment contained diseased larvae. The effect of Blattisocius activity in reducing overcrowding and incidence of disease is revealed in the individual analyses of six wheat-depleted habitat allotments shown below.
Anagasta larvae per allotment ranged from 39 to 78 and averaged 60. By. October, 1962, the Anagasta population in this ecosystem was under complete regulation by Blattisocius, with disease a negligible factor.

The 1962 outbreak of Anagasta in Ecosystem XII was followed by a bacterial epizootic. This is in contrast to the 1959 outbreak in Ecosystem IV, which was not thus followed. This difference may have been an effect of differences in larval crowding. In 1962, the outbreak lasted for 23 days with an average of 50 moths emerging per day. In 1959, the outbreak lasted only 12 days, with 100 moths emerging per day. Presumably in the latter case the great internecine strife among newly hatched larvae precluded overcrowding. At the peak of the outbreak in Ecosystem XII, an analysis of a habitat allotment showed 89 diseased larvae among a total of 117 .

In late June and early July, 1962, a bacterial epizootic occurred in Ecosystem II where the Anagasta population was under regulation by the wheat supply. The maximum number of diseased larvae in a habitat allotment was 57 among a total of 90 .

The events preceding this epizootic, and presumably causing it, were as follows:

In November, 1961, vermiculite depth was increased from 5 to $8 \mathrm{~mm}$. The consequent decrease in Exidechthis parasitization was such that during the latter part of December, 1961, and the early part of January, 1962, 527 Anagasta larvae escaped attack. This resulted in habitat allotment overcrowding in February, 1962, as evidenced by

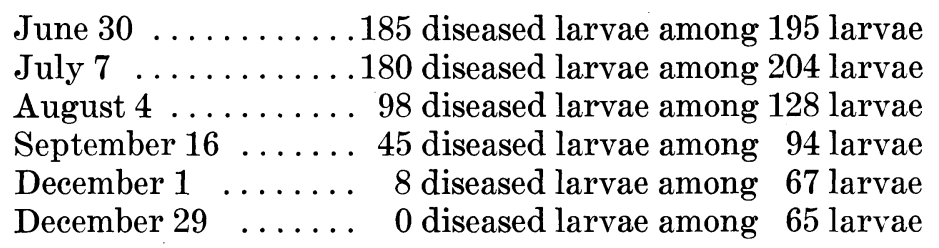

During 1962, five of 10 habitat allotments analyzed were completely free of disease. In these five, the total number of the emigration of 40 immature larvae from the habitat allotments.

The emergence of 527 Anagasta 
adults during a 24-day period ending March 15, resulted in heavy egg deposition and the development of a large Blattisocius population ranging in abundance from five mites per moth (Feb. 23) to 30 mites per moth (Mar. 8). The reduced adult Anagasta emergence from May 1 to May 20, due to Blattisocius-caused egg mortality and Exidechthis-caused larvae mortality during the preceding March and April, consisted of 14 adults of which one-half were females. Some of these may not have oviposited because of lack of mating. Also, during this 20-day period Exidechthis replaced 22 Anagasta. The consequent lack of Anagasta eggs decimated the Blattisocius population so that the surviving progeny of the early March emergence of Anagasta (181 adults emerging during a 17-day period ending June 10) reproduced, unrestricted by Blattisocius. The consequent overcrowding induced the bacterial epizootic.

Natural enemy-prey interactions not only tend to preclude the incidence of disease, but may so relax the intensity of interspecific competition by two or more host species for a common resource that their coexistence is rendered possible. This phenomenon was reported by Utida (1960) who observed it in laboratory populations of two species of the bean weevils (Callosobruchus spp.) parasitized by a species of Heterospilus. However, in these experiments the violent fluctuations of the weevil population, the high level of parasite density, and the manipulation of food conservation indicated that the action of the parasite was not regulative. Field observations in south China by the senior author (Flanders, 1956) on the interrelations of two potentially very destructive citrus insects, the red scale, Aonidiella aurantii (Mask.) and the yellow scale, A. citrina (Coq.) indicated that their coexistence on the citrus tree depended on their populations being maintained at low densities by natural enemies.

Apparently, as Crombie (1947), Nicholson (1957), and Williamson (1957) have pointed out, organisms with the same needs and habits may coexist in the same place if through the action of their natural enemies their demand for the same requisites is not in excess of the immediate supply.

\section{CONCLUSIONS}

We conclude from the operation of 17 Anagasta ecosystems during the past six years (and also from field observations) that in any ecosystem, natural or artificial, there are two primary biotic forces which underlie the regulation of animal populations-auto-mortality (including territoriality) and mortality by natural enemies, the operation of the latter precluding the operation of the former. Many ecosystems include at least one phytophagous animal whose population density is regulated by natural enemies well within the limits set by the food supply. The population of that animal is self-perpetuating and persistent, usually characterized by overlapping generations and possessing refuges which prevent its annihilation by natural enemies.

A natural enemy/prey-regulative interaction tends toward uniformity in abundance of all the organisms concerned. "Outbreaks" of phytophagous animals may be an effect of a temporary disruption of cooperative regulatory action by two or more species of predators under circumstances when each alone would be nonregulatory. Ordinary fluctuations in abundance of phytophagous animals may occur because of variations in their auto-mortality.

A predator population can attain balance merely by adjusting its numbers to the abundance of a plant-governed prey population, the predator's abundance 
then varying directly with that of the prey population. As a consequence, animal populations exhibit two types of equilibrium (balance), reciprocal and nonreciprocal.

Natural enemy reproduction increases and decreases with prey density in both types of balance. However, prey reproduction increases and decreases with natural enemy density only when the enemy balance is reciprocal, the individual prey being acted upon more severely by a high density natural enemy population than by a low density population.

When balance is nonreciprocal, prey reproduction is unaffected by natural enemy density - the prey/natural enemy ratio being practically constant. Consequently, natural enemies occur in maximum numbers only when balance is nonreciprocal.

The reciprocal/nonreciprocal differentiation in balance in the Anagasta ecosystem was found to be an effect of differential abiotic protection of the prey from the natural enemy.

When this degree of protection is increased above the "threshold of security," the Anagasta population is deter- mined by the amount of wheat rather than by the natural enemy, the population balance of the latter then being nonreciprocal; when it is decreased below the "threshold of security," the natural enemy population eliminates the Anagasta population and consequently, itself.

The attainment of reciprocal balance in the Anagasta ecosystems constitutes proof of Nicholson's (1933) Law that for population regulation "the population controlled must govern the action of the controlling factor." This attainment is manifested by the "face" (appearance) of the ecosytem remaining uniform for 20 or more generations of $A n a$ gasta, and the wheat being rendered unlimited as a resource through its preclusion as a regulative factor.

The Anagasta ecosystems as now constituted are to be used in illustrating some of the manifold roles played by abiotic and biotic agencies in population dynamics. The roles of disease and natural enemy mortality, separately and in combination, are currently under investigation, in conjunction with our colleague, Dr. I. M. Hall.

\section{ACKNOWLEDGMENTS}

The construction of this article and the conclusions presented, herein, were improved by the incorporation of constructive criticisms submitted by Professor C. A. Fleschner, Professor C. B. Huffaker, and Dr. A. J. Nicholson. The identification of the epizootic microorganism attacking the laboratory populations of Anagasta kühniella as a sporeforming crystalliferous bacterium was made by Professor I. M. Hall. 


\section{LITERATURE CITED}

Allee, W. C., O. Park, A. E. Emerson, T. Park, and K. P. Schmidt

1949. Principles of animal ecology. W. B. Saunders Co., Philadelphia. 837 pp.

BAtes, M., and P. S. Humphery

1956. The Darwin reader. C. Scribner's Son, New York. 470 pp.

BURneTt, Thomas

1958. A model of host-parasite interaction. Proc. 10th Internatl. Congr. Ent. 2:675-86.

Chapman, R. N.

1927. Animal ecology with special reference to insects. Mimeog. Burgess \& Roseberry Co., Minn. 370 pp.

Clausen, C. P.

1956. Biological control of insect pests. U. S. Dept. Agr. Tech. Bull. 1139. 151 pp.

CoMpere, H., and H. S. SMITH

1932. The control of the citrophilus mealybug Pseudococcus gahani by Australian parasites. Hilgardia 6:585-618.

Crombie, A. C.

1947. Interspecific competition. J. Animal. Ecol. 16:44-73.

Elton, C.

1942. Voles, mice and lemmings. Problems in population dynamics. Oxford. Clarendon Press. $496 \mathrm{pp}$.

1946. Competition and the structure of ecological communities. J. Animal Ecol. 15:54-68.

Fisher, R. C.

1962. The effect of multiparasitism on populations of two parasites and their host. Ecology 43:314-16.

FlaNders, S. E.

1935. Effect of host density on parasitism. J. Econ. Entomol. 28:898-900.

1944. Biological control of the potato mealybug. J. Econ. Entomol. 37:312.

1949. Using black scale as a "foster host." Calif. Citrog. 34:222-24.

1953. Variations in susceptibility of citrus-infesting coccids to parasitization. J. Econ. Entomol. 46:266-69.

1956. Struggle for existence between red and yellow scales. Calif. Citrog. 41:396-403.

1957. The complete interdependence of an ant and a coccid. Ecology 38:535-36.

1958. The Ephestia-Idechthis ecosystem for illustrating population dynamics. Ecology 39: 545-47.

1959a. Areas of discovery in the Ephestia-Idechthis ecosystem delimited by vermiculite. Ecology 40:165.

1959b. Biological control of Saissetia nigra (Nietn.) in California. J. Econ. Entomol. 52:596600.

Flanders, S. E., and Max E. Badgley

1960. A host-parasite interaction conditioned by predation. Ecology 41:363-65.

Flanders, S. E., and J. L. GressitT

1958. The natural control of California red scale in China. Quart. Bul. Calif. State Dept. Agr. 49:23-33.

GaUse, G. F.

1934. The struggle for existence. Williams \& Williams, Baltimore. $163 \mathrm{pp}$.

Graham, S. A.

1939. Forest insect populations. Ecol. Monog. 9:301-10.

LATHAM, ROGER M.

1952. The predator question. Penn. Game News, Spec. Issue No. 5.

LAUCKHART, J. B.

1962. Wild-life population fundamentals. Trans. N. Amer. Wildlife Conference 27:233-42.

MaRCHAL, $\mathrm{P}$.

1908. The utilization of auxiliary entomophagous insects in the struggle against pests injurious

MUIR, F. to agriculture. Pop. Sci. Month. 72:352-419.

1913. Presidential Address. Proc. Hawaii Entomol. Soc. 3:28-42.

Nicholson, A. J.

1933. The balance of animal populations. J. Animal Ecol. 2:132-78.

1937. The role of competition in determining animal populations. Jour. Council Sci. and Indust. Res. 10:101-06. 
1950. Population oscillations caused by competition for food. Nature 165:476.

1954a. An outline of the dynamics of animal populations. Austral. Jour. Zool. 2:9-65.

1954b. Experimental demonstrations of balance in populations. Nature 173:862-63.

1957. The self-adjustment of populations to change. Cold Spring Harbor Symposia on Quant. Biol. 22:153-73.

1958. Dynamics of insect populations. Ann. Rev. Entomol. 3:107-36.

ParK, ThOMAS

1946. Some observations on the history and scope of population ecology. Ecol. Monogr. 16: 313-20.

PicketT, A. D.

1961. The ecological effects of chemical control practices on arthropod populations in apple orchards in Nova Scotia, Canada. IUCN Symposium WARszawA 15-24. 1960. 7:19-24.

RILEY, C. V.

1893. Parasitic and predaceous insects in applied entomology. Insect Life 6:130-41.

Slobodkin, L. B.

1962. Predation and efficiency in laboratory populations. British Ecol. Soc. Symposium 2: 223-41.

SMITH, H. S.

1935. The role of biotic factors in the determination of population densities. J. Econ. Entomol. 28:873-98.

1939. Insect populations in relation to biological control. Ecol. Monogr. 9:311-20.

Solomon, M. E.

1947. Mortality required to prevent population increase. Nature 159:848-49.

1949. The natural control of animal populations. J. Animal Ecol, 18:1-35.

TAKAHASHI, $\mathrm{F}$.

1959. The effect of host-finding efficiency of parasites on the cyclic fluctuations of populations in the interacting system of Ephestia and Nemeritis. Jap. Jour. Ecol. 9:88-93.

Timberlake, P. H.

1913. Preliminary report on the parasites of Coccus hesperidum in California. J. Econ. Entomol. 6:293-303.

UTIDA, S.

1950. On the equilibrium state of the interacting population of an insect and its parasite. Ecology 31:165-75.

1960. Experimental studies on the interaction between the bean weevils and their parasitic wasps. XI Int. Kong. f. Entomol. Vien. 1:731-34.

VAN DER VECHT, J.

1951. On some aspects of the numerical variations of insects in the tropics. Trans. IX Internatl. Congr. Entom. 2:272-77.

VARLEX, G. C.

1960. Pests of standing crops. Nature 188:360-62.

WHEELER, W. M.

1911. Insect parasitism and its peculiarities. Pop. Sci. Month. 79:431-49.

1928. The social insects, their origin and evolution. Harcourt, Brace \& Co., N. Y. 378 pp.

Williamson, M. H.

1957. An elementary theory of interspecific competition. Nature 180:422-25.

WoODWORTH, C. W.

1908. The theory of the parasitic control of insect pests. Science 1908:227-30. 

The Anagasta ecosytem, since its inception seven years ago, has proven to be an excellent means for studying in detail the action and effects of biotic agents on population dynamics, the incidence of disease and the conservation of plant material.

To date this ecosytem has demonstrated that (1) a natural enemy may exhibit two types of "balance," one characterized by prey relation which is reciprocally regulative, the other by a prey relation which is not reciprocally regulative: a natural enemy population when in reciprocal balance precludes the attainment of such a balance by the prey (and its food supply); when in non-reciprocal balance the natural enemy does not preclude the prey from attaining a reciprocal balance (with its food supply); (2) the natural enemy attains its greatest annual abundance when it is not preyregulative; (3) an adult predator population when prey-regulative exceeds, numerically, the adult prey population if the predator's period of reproductivity is inherently shorter than its developmental period; (4) the natural enemy, even when nonregulative, tends to preclude bacterial epizootics; (5) long-interval fluctuations ("outbreaks") of the Anagasta populations occur when under general regulation by Blattisocius in cooperation with Exidechtbis, these outbreaks following the occasional complete replacement of adult Anagasta by adult Exidechthis and the consequent reduction of the Blattisocius populations by starvation; $(6)$ the population fluctuations of full-fed Anagasta larvae attain their maxima in amplitude and frequency when natural enemies are present but nonregulative, the fluctuations apparently being initiated through the internecine strife of the newly hatched Anagasta larvae; (7) the inability of the natural enemy (whose increase or decrease is a function of prey density) to regulate its prey population is an effect of over-protection of the prey either structurally, spatially, or chemically; (8) regulative parasitism precludes the operation of such density-dependent mortality factors as internecine strife and predatism; and (9) the reciprocal density regulation of the Anagasta population and its natural enemy population conserves the maximum amount of plant material upon which Anagasta subsists, and thus permits the maximum number of Anagasta generations per given amount of such material.

Laboratory, as well as field studies, show that the ultimate effect of the prey-predator interaction, in general, is to conserve plant material during intervals between the periodic replacements of such material.

These findings are preliminary to further studies based on the Anagasta ecosystem involving the manifold roles which interacting abiotic and biotic factors play in population dynamics. 
The journal HILGARDIA is published at irregular intervals, in volumes of about 650 to 700 pages. The number of issues per volume varies.

Single copies of any issue may be obtained free, as long as the supply lasts; please request by volume and issue number from:

$$
\begin{aligned}
& \text { Agricultural Publications } \\
& \text { University Hall } \\
& \text { University of California } \\
& \text { Berkeley 4, California }
\end{aligned}
$$

The limit to nonresidents of California is 10 separate titles. The limit to California residents is 20 separate titles.

The journal will be sent regularly to libraries, schools, or institutions in one of the following ways:

1. In exchange for similar published material on research.

2. As a gift to qualified repository libraries only.

3. On a subscription basis $-\$ 7.50$ a year paid in advance. All subscriptions will be started with the first number issued during a calendar year. Subscribers starting during any given year will be sent back numbers to the first of that year and will be billed for the ensuing year the following January. Make checks or money orders payable to The Regents of The University of California; send payment with order to Agricultural Publications at above address. 